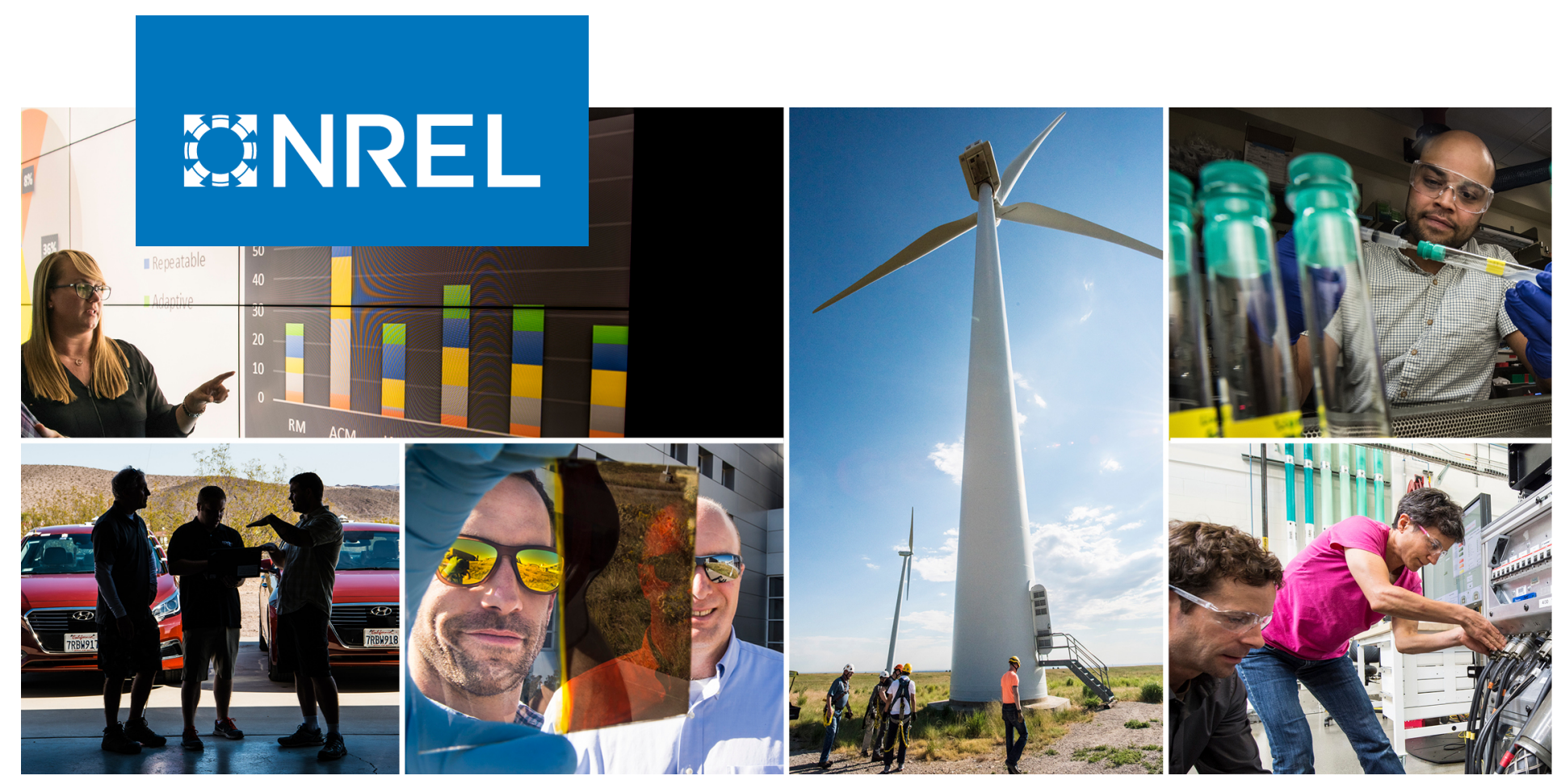

\title{
A Circular Economy for Lithium-Ion Batteries Used in Mobile and Stationary Energy Storage: Drivers, Barriers, Enablers, and U.S. Policy Considerations
}

Taylor L. Curtis, Ligia Smith, Heather Buchanan, and Garvin Heath

NREL is a national laboratory of the U.S. Department of Energy Office of Energy Efficiency \& Renewable Energy

Operated by the Alliance for Sustainable Energy, LLC

This report is available at no cost from the National Renewable Energy Laboratory (NREL) at www.nrel.gov/publications.
Technical Report

NREL/TP-6A20-77035

Revised March 2021 


\section{GNREL}

\section{A Circular Economy for Lithium-Ion Batteries Used in Mobile and Stationary Energy Storage: Drivers, Barriers, Enablers, and U.S. Policy Considerations}

Taylor L. Curtis, Ligia Smith, Heather Buchanan, and Garvin Heath

\section{Suggested Citation}

Curtis, Taylor L., Ligia Smith, Heather Buchanan, and Garvin Heath. 2021. A Circular Economy for Lithium-Ion Batteries Used in Mobile and Stationary Energy Storage: Drivers, Barriers, Enablers, and U.S. Policy Considerations. Golden, CO: National Renewable Energy Laboratory. NREL/TP-6A20-77035.

https://www.nrel.gov/docs/fy21osti/77035.

NREL is a national laboratory of the U.S. Department of Energy Office of Energy Efficiency \& Renewable Energy Operated by the Alliance for Sustainable Energy, LLC

This report is available at no cost from the National Renewable Energy Laboratory (NREL) at www.nrel.gov/publications.

Contract No. DE-AC36-08GO28308
Technical Report NREL/TP-6A20-77035

Revised March 2021

National Renewable Energy Laboratory 15013 Denver West Parkway Golden, CO 80401 303-275-3000 • www.nrel.gov 


\section{NOTICE}

This work was authored by the National Renewable Energy Laboratory, operated by Alliance for Sustainable Energy, LLC, for the U.S. Department of Energy (DOE) under Contract No. DE-AC36-08GO28308. This work was supported by the NREL Planning and Assessment Circular Economy for Energy Materials Steering Committee. The views expressed herein do not necessarily represent the views of the DOE or the U.S. Government.

This report is available at no cost from the National Renewable Energy Laboratory (NREL) at www.nrel.gov/publications.

U.S. Department of Energy (DOE) reports produced after 1991 and a growing number of pre-1991 documents are available free via www.OSTI.gov.

Cover Photos by Dennis Schroeder: (clockwise, left to right) NREL 51934, NREL 45897, NREL 42160, NREL 45891, NREL 48097, NREL 46526.

NREL prints on paper that contains recycled content. 


\section{Errata}

This report, originally published in February 2021, has been revised in March 2021 to correct the authors' names and order; correct the spelling of a name and their affiliation in the acknowledgments section; correct grammatical errors; and provide clarification in certain sections of the report. 


\section{Acknowledgments}

We gratefully acknowledge the National Renewable Energy Laboratory (NREL) Planning and Assessment Circular Economy for Energy Materials Steering Committee for its funding support. We also acknowledge John "Jack" Wadleigh and Anabelle Chaffin of NREL for their research support. And we thank the following report reviewers for their time and expertise: Kristen Ardani, Doug Arent, Dan Bilello, Nate Blair, Wayne Hicks, Mike Meshek (editor), and Gian Porro of NREL; Ken Boyce, UL; Kathy Lett, U.S. Environmental Protection Agency (EPA), Headquarters; Daniel Stoehr, Daniels Training Services, Inc.; David Wagger, Institute for Scrap Recycling Industries; Stephanie Shaw, Electric Power Research Institute; Jordan Rivera and Neal Suchak, U.S. Department of Transportation, Headquarters; and Jessica Citrola, North Carolina Department of Environmental Quality.

We also thank the following for their time and expertise: Charles (Chuck) Figur, U.S. EPA, Region 8; Chris Newman, U.S. EPA Region 8; Lia Yohannes, U.S. EPA, Headquarters; Amanda Cotton and John Gilkeson, Minnesota Pollution Control Agency; Jennifer Martin, Illinois Sustainable Technology Center; Anthony (Tony) Burrell, and Maggie Mann, NREL; Jon Weisman, (formerly) Tesla; Laura Allerston, Aceleron Energy; Paulina Kolic, and Teresa Bui, CalRecycle; and Carl Smith, Call2Recycle. 


\section{List of Acronyms}

ANSI

BES

CalEPA

DOE

DOT

EoL

EPA

EV

IATA

IBC

ICAO

IEEE

IMDG

$\mathrm{kg}$

LiB

Li-BES

$\mathrm{Mt}$

NEC

NFPA

NREL

OECD

PV

R\&D

RCRA

SEIA

TSDF

UL
American National Standards Institute

battery energy storage

California Environmental Protection Agency

U.S. Department of Energy

U.S. Department of Transportation

end-of-life

Environmental Protection Agency

electric vehicle

International Air Transport Association

International Building Code

International Civil Aviation Organization

Institute of Electrical and Electronics Engineers

International Maritime Dangerous Goods

kilogram

lithium-ion battery

lithium-ion battery energy storage

metric tons

National Electrical Code

National Fire Protection Association

National Renewable Energy Laboratory

Organization for Economic Cooperation and Development

photovoltaic

research and development

Resource Conservation and Recovery Act of 1976

Solar Energy Industries Association

treatment, storage, and disposal facility

Underwriters Laboratories 


\section{Executive Summary}

Large-format lithium-ion batteries ( $\mathrm{LiB}$ ) are an essential component to a zero-carbon energy transition in the United States and around the world. National and international policy focused on reducing carbon emissions and increasing electric grid resiliency continue to drive demand for mobile and stationary LiB battery energy storage (BES) (BNEF 2020; Wood MacKenzie and ESA 2020). In the U.S. alone, stationary BES (to support renewable energy generation) is expected to grow from 523 megawatts annually to 7.3 gigawatts in 2025 , and U.S. roads are projected to see 46 million passenger electric vehicles (EV) by 2035 (BNEF 2020; Wesoff 2020; Wood MacKenzie and ESA 2020).

The rapid growth and expected continual demand for mobile and stationary lithium-ion BES (LiBES) has led to global environmental and supply chain concerns. Critical materials (e.g., cobalt, lithium, nickel, graphite, manganese) used in LiBs are finite and mined in only a few regions around the world. Moreover, they are often found and refined in countries with less-stringent environmental and human health regulations. The demand for graphite, lithium, and cobalt is expected to increase by nearly $500 \%$ by 2050 and experts expect a shortage of nickel within in 5 6 years if current trends for mobile and stationary Li-BES persist (World Bank 2020; Mayyas, Steward, and Mann 2019; ReCell Center 2019c).

Moreover, as BES capacity increases in the United States so will the volume of spent LiBs (Bade 2019). Estimates based on a 10-year lifetime assumption found that the volume of LiBs that have reached the end of their utility for EV applications alone could total two million units (four million metric tons) annually by 2040 in the United States (Richa et al. 2014; Ai and Borucki 2018). Retirements that are due to early failure (e.g., crashes and battery replacements), as well as BES deployment beyond earlier expectations, will increase these projections (Gibson 2019; Ai and Borucki 2018; Richa et al. 2014).

As first-generation EV batteries reach end-of-life in the U.S. and the global demand for critical LiB materials increases U.S. industry stakeholders, regulators, and policymakers are starting to (1) consider solutions to drive and enable environmentally sustainable LiB management decisions and behaviors and (2) identify barriers to a circular economy for LiBs. Circular economy principles attempt to transition from a "take-make-consume-dispose" linear economic system to a circular system that allows for the long life, high performance, and the reuse/recovery of products and materials (Ellen MacArthur Foundation 2016).

In this report we analyze drivers, barriers, and enablers to a circular economy for LiBs used in mobile and stationary BES systems in the United States. We also analyze federal, state, and local legal requirements that apply to the reuse, recycling and disposal of LiBs as well as the legal liability associated with noncompliance. Finally, we provide an overview of policies and initiatives in the United States that expressly address reuse/recovery and disposal of large-format LiBs. Some of our findings are listed below:

\section{Drivers of a Circular Economy for LiBs}

New and expanded market opportunities, job creation, supply chain stability, and reduced negative environmental impacts are drivers for federal, state, and local investment in reuse and recovery of LiBs. The secondary market for repurposed EV LiBs could include stationary and 
mobile BES system applications as well as other applications that require less battery cycling (e.g., drones and forklifts) (Kelleher Environmental 2019; Engel, Hertzke, and Siccado 2019; Neubauer et al. 2015; Elkind et al. 2014). Existing domestic businesses (e.g., auto dismantlers, manufacturers, repair shops, mechanics, third-party recycling companies, and lifecycle management companies) could expand to include LiB repair, recycling, handling, and transport services. New companies could emerge to provide reuse and recycling products and services that include 1) collection, transport, disassembly of the battery pack; 2) diagnostic and screening tests to identify battery chemistries; and 3) repair, refurbishment, reassembly, installation, recycling, reverse logistics, and resale. (Kelleher Environmental 2019). In addition, domestic recovery of critical materials (e.g., lithium, cobalt, nickel, manganese, and graphite) from LiBs could reduce U.S. dependence on foreign markets and imports and bolster domestic production and manufacturing (ReCell 2019b; NREL 2019a; Jacoby 2019; Gaines 2018; Patel 2017; Elkind 2014). Secondary use of LiBs can reduce disposal of reusable products, while recycling-based resource recovery of LiBs could divert valuable materials from landfills (Salim et al. 2019; ReCell Center 2019a, 2019b; Argonne 2019; Jacoby 2019; NREL 2019a; Patel 2017; Elkind 2014). Further, extending the useful life of LiBs through reuse lowers lifecycle environmental impacts by reducing energy output and the costs of obtaining, transporting and refining virgin materials required to manufacture new LiBs (ReCell Center 2019a, 2019b; Salim et al. 2019).

Cost savings, increased profits, and enhanced competitiveness are drivers to increase private investment in product and process innovation and the reuse and recovery of LiBs. Manufacturers and system owners could sell used LiB packs to generate revenue or donate LiB packs for charitable use and receive a tax credit. Manufacturers could lower manufacturing costs by reusing recovered materials from customer warranty returns, manufacturing scrap, and other retired LiBs. System owners and third-party recyclers may also generate revenue by selling recovered materials into commodity markets (Salim et al. 2019; ReCell Center 2019b; Jacoby 2019; ReCell Center 2019d; NREL 2019a; Xu et al. 2018; Patel 2017; Elkind 2014). Moreover, companies that engage in environmentally sustainable business practices such as reuse and recycling may in turn increase consumer confidence in secondary market products, and their overall competitiveness in the marketplace (Salim et al. 2019; Xu et al. 2018).

\section{Barriers to a Circular Economy for LiBs}

The reuse and recycling market for LiBs in the United States is nascent but there are limited services and infrastructure in place to support reuse and recycling of LiBs. Moreover, the infrastructure, processes, and technology currently in place and available for the reuse and recycling of LiBs are not optimized for efficient cost-effective reconditioning or recovery of materials. As a result, reuse and recycling options in the United States are less readily available and are more costly than cheaper, more accessible disposal options.

There is also limited motivation or incentives for private investment in new and expanded BES circular economy market opportunities. There is limited publicly available information and data available regarding the value of, and markets for, reused and recovered LiBs to inform investment decisions. The applicability of state and local interconnection, fire, building, and electrical regulations to BES systems is often unclear, making it difficult to determine viable secondary use applications. In turn there is limited publicly available information and projects to demonstrate the quality, performance, safety, and technical viability of reused and refurbished 
LiBs which may also impact consumer trust and confidence in the reuse of LiBs for mobile and stationary application. Moreover, federal and state solid waste and federal transportation laws often regulate LiBs destined for resource recovery in the same manner as LiBs destined for disposal, which does not provide an incentive for recycling especially when the economics and accessibility of disposal are more favorable.

\section{Enablers to a Circular Economy for LiBs}

Policy ${ }^{1}$ is needed to enable a circular economy for LiBs in the United States. Government funded research and development (R\&D) and analysis could enable private investment in the early stages of new and expanded BES market opportunities by providing answers to questions that could help alleviate market uncertainty and lead to more efficient cost-effective technologies, processes and services for the reuse and recycling of LiBs. For example, vehicle diagnostic and degradation data, as well as improved methods of monitoring batteries in the field could aid life expectancy projections, which can be used to inform supply forecasts and help identify viable secondary use applications. Policy can also mandate or incentivize the reuse and recycling of $\mathrm{LiBs}$, which is needed to enable sustainable material management practices for LiBs until the market matures and the economics of reuse and recycling are more competitive with disposal. For instance, government subsidies, grants and awards could be used to reduce financial risk and make early investment for private industry more desirable. Policies could also mandate reuse or recycling or prohibit disposal and they could also incentivize reuse and recycling by reducing the regulatory burden and legal liability associated compared to disposal.

\section{Federal, State, and Local Legal Requirements}

In this report, we also analyze federal, state, and local legal requirements that apply to the reuse, recycling and disposal of LiBs as well as the legal liability associated with noncompliance. Our analysis of state and local interconnection, fire, building, and electrical regulations in the United States revealed that these regulations are often complex and vary by jurisdiction and typically do not explicitly address BES systems. Anecdotal evidence suggests the variability and ambiguity of how these regulations apply to BES systems has created uncertainty that may impact reuse of LiBs for grid-tied and off-grid applications. We also analyze federal solid waste requirements pursuant to the Resource Conversation and Recovery Act of 1976 (RCRA) which may apply to large-format LiBs accumulated or stored before recycling or disposal and those being recycled or disposed of. We found that large-format LiBs are often regulated as RCRA hazardous solid waste or universal hazardous waste necessitating compliance with stringent generation, handling, storage, treatment, recycling, and disposal requirements which carry civil and criminal penalties for noncompliance. Moreover, LiBs destined for resource recovery are often regulated in the same manner as those being disposed, which does not provide a regulatory incentive to recycle LiBs. In addition, anecdotal evidence suggests that there is confusion and jurisdictional discrepancies regarding whether certain reuse and recovery processes (e.g., cathode relithiation) for LiBs triggers RCRA regulation or not.

\footnotetext{
${ }^{1}$ We use "policy" in this report broadly to include not only federal, state, and local statutory and regulatory requirements but also government initiatives and goals.
} 


\section{LiB Material Management Policies}

Finally, we provide an overview of policies and initiatives in the United States that expressly address reuse/recovery and disposal of large-format LiBs. We found no U.S. federal policies that address the reuse of or EoL management options for LiBs used in stationary and mobile BES application. North Carolina and California are the only U.S. states we found with policies that directly address reuse and EoL management options for LiBs used in BES systems. North Carolina's law requires state agencies to study and recommend policy regarding the reuse, recycling, and disposal of stationary energy storage system batteries. Similarly, California's law requires the California Environmental Protection Agency to conduct a study and recommend policy to reach a goal of $100 \%$ reuse and recycling of EV LiBs. Hawaii also has proposed a bill that, if enacted, would require a comprehensive study to determine best practices for disposing of and recycling clean energy materials, including batteries. In addition to the state law, California also has a state-led initiative in place to study EV and stationary BES decommissioning and EoL management options. These recent policies may signal a growing trend to prioritize sustainable material management practices for early retired and EoL batteries used for stationary and mobile BES application.

Our results are based on legal and literature-based research. In addition, our results incorporate feedback and information we received from a series of interviews conducted through teleconference and email exchange with a diverse group of mobile and stationary BES experts, including academic and research organizations, industry associations, LiB manufacturers, $\mathrm{LiB}$ reuse/repair/recycling companies, consultants, as well as U.S. federal and state regulators, and policymakers. The questions used in each interview were tailored specifically to the industry stakeholders' areas of expertise. While this report addresses stationary and mobile LiBs, much of the information and experience with $\mathrm{LiB}$ reuse and EoL material management is derived from increased management of spent EV LiBs in the United States. Moreover, this report is limited to U.S. LiB-BES regulatory, policy, and market analysis.

This report is intended to inform decisionmakers, including those involved with policy design; it does not endorse any particular policy mechanism over another, nor does it assess all regulatory requirements or the impacts that those requirements and policies may have on U.S. BES markets or related commodity markets. 


\section{Table of Contents}

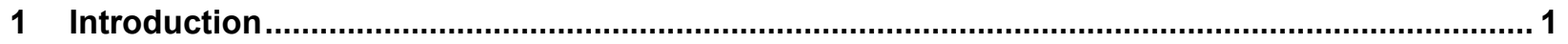

2 Drivers, Barriers, and Enablers to a Circular Economy for LiBs............................................. 6

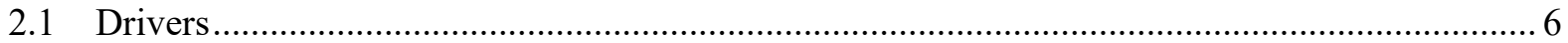

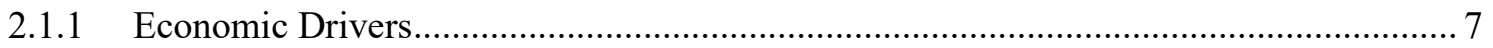

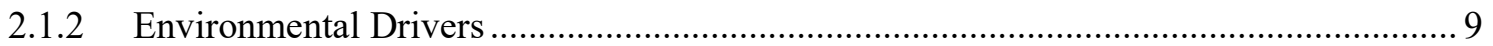

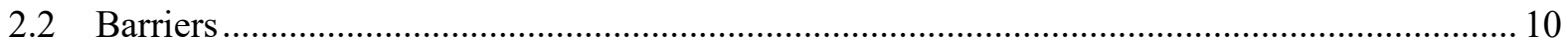

2.2.1 Technology, Infrastructure, and Process Barriers .................................................... 11

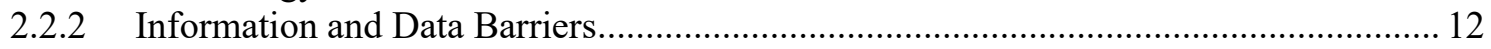

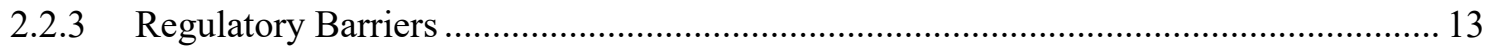

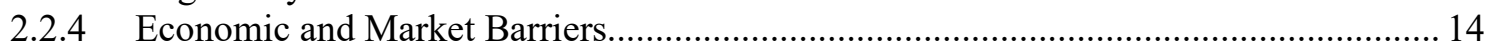

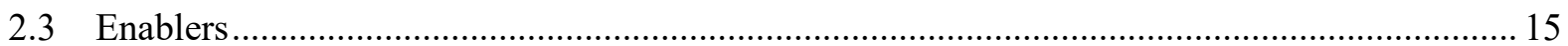

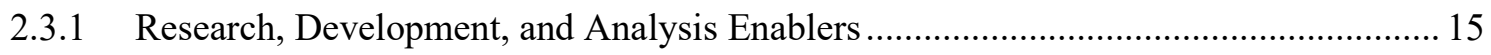

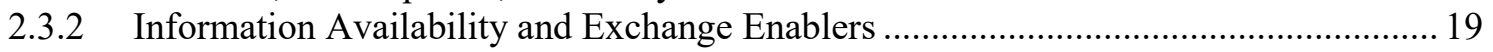

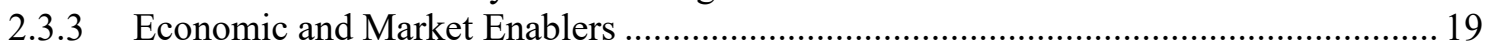

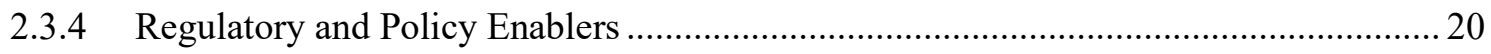

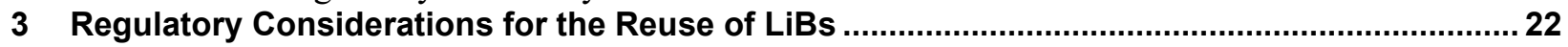

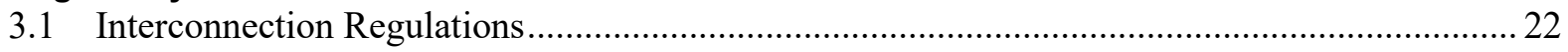

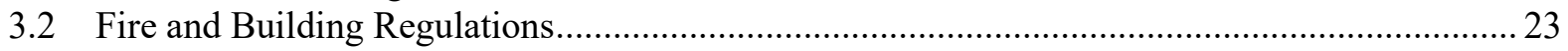

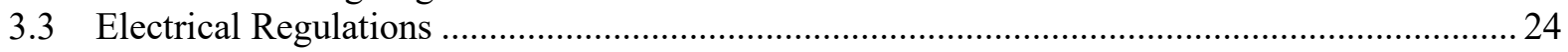

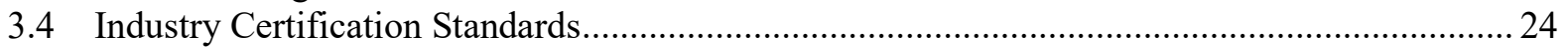

4 Statutory and Regulatory Considerations for the Reuse, Recycling, and Disposal of LiBs ...... 26

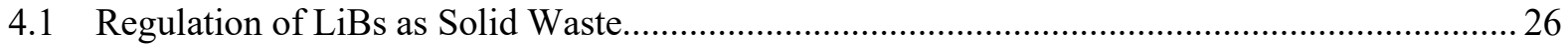

4.1.1 Materials Excluded from the Definition of Hazardous Solid Waste................................ 28

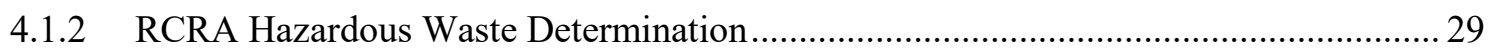

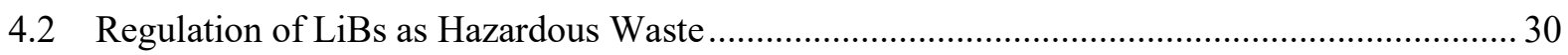

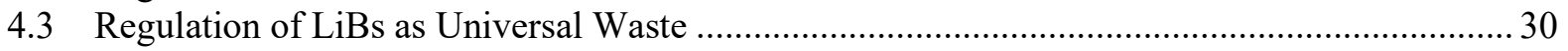

4.4 Comparison of Hazardous Waste and Universal Waste Handling, Storage, and Transport

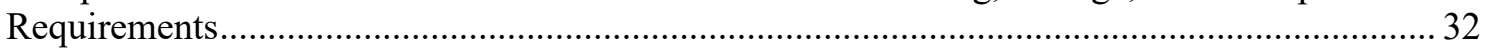

4.4.1 Generator and Handler Requirements .................................................................... 32

4.4.2 Treatment, Storage, and Disposal Facility and Destination Facility Requirements ....... 34

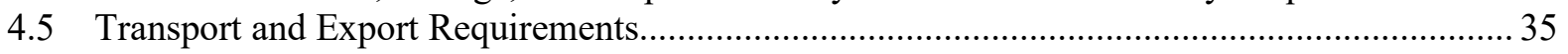

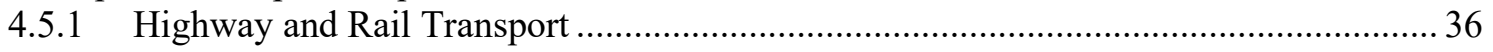

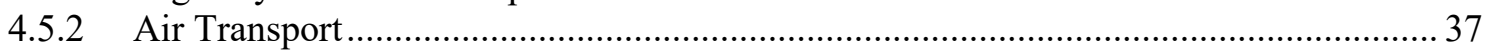

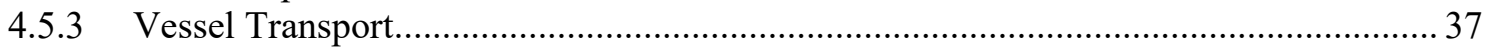

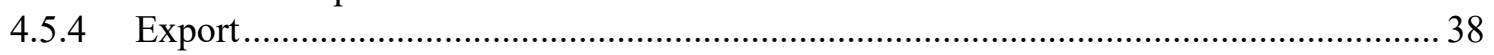

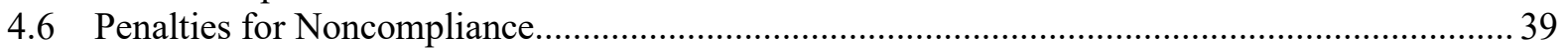

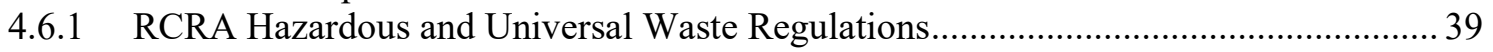

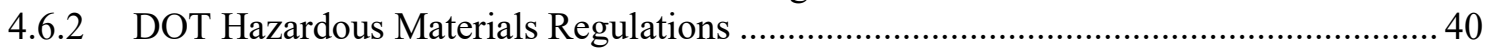

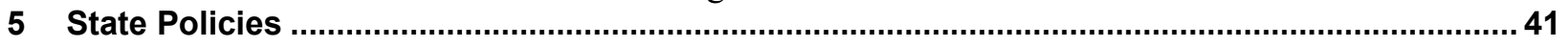

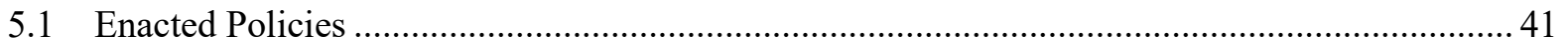

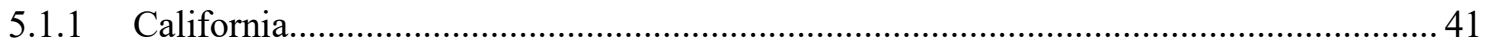

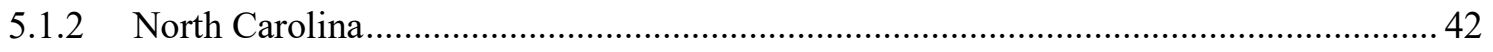

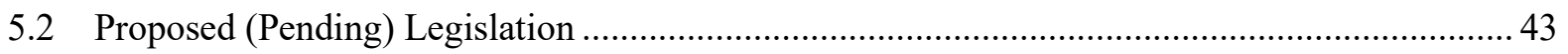

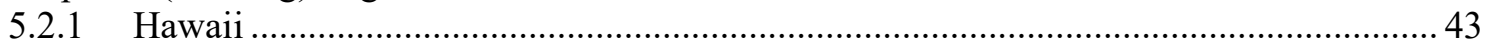

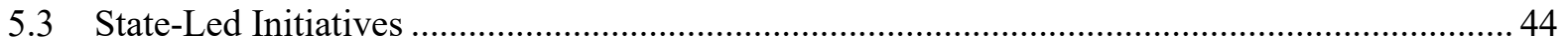

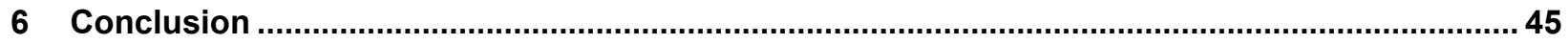

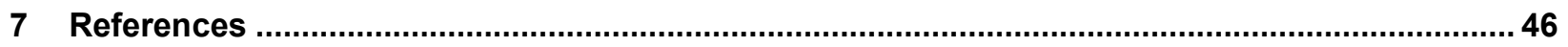

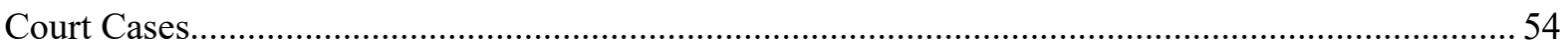

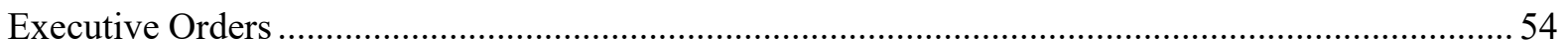

ix 


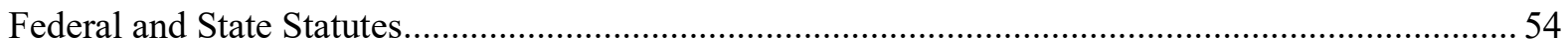

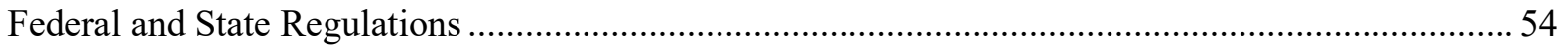

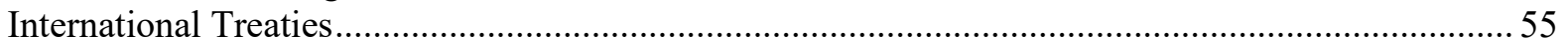

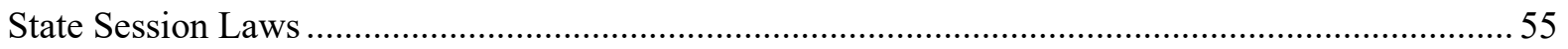

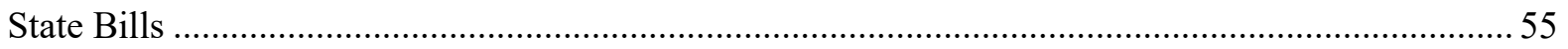

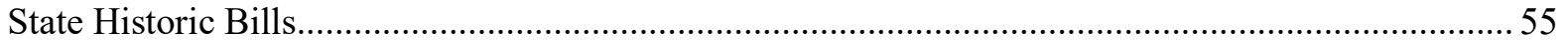

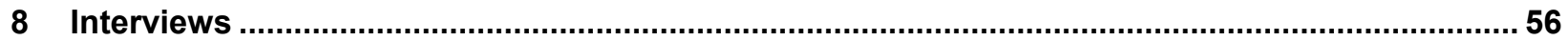

\section{List of Figures}

Figure 1. A circular economy for LiBs 2

Figure 2. State large-format battery material management policies (enacted, pending, and state-led initiatives).

\section{List of Tables}

Table 1. Drivers of a Circular Economy for LiBs................................................................................. 7

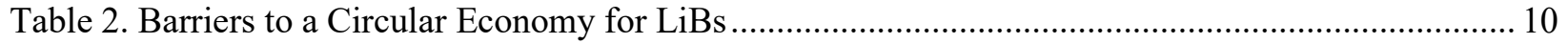

Table 3. Potential Enablers to a Circular Economy for LiBs............................................................. 15

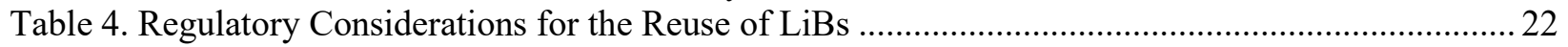

Table 5. Statutory and Regulatory Considerations for the Reuse, Recycling, and Disposal of LiBs ......... 26

Table 6. Federal Hazardous Waste Generator and Universal Waste Handler Requirements ${ }^{\mathrm{a}}$.................... 32

Table 7. Federal Hazardous Waste Transporter and Universal Waste Transporter Requirements ${ }^{\mathrm{a}}$............ 35 


\section{Introduction}

The global market for large-format lithium-ion batteries $(\mathrm{LiB})^{2}$ continues to grow in response to increasing demand in electric vehicles $(\mathrm{EVs})^{3}$ and energy storage. From 2013 to 2020, total cumulative U.S. energy storage deployments reached approximately 1,600 megawatts, of which LiBs accounted for $99 \%$ of the total market share (Wood MacKenzie and ESA 2020; Bade 2019). From 2011 to 2020 , total cumulative U.S. passenger EV sales ${ }^{4}$ reached approximately 1.4 million units, of which LiBs accounted for most of the market share (BNEF 2020; DOE n.d.; Coffin and Horowitz 2018).

State and federal policy focused on electric grid resiliency and on zero-emission energy generation and transport will continue to drive the demand for mobile - and - stationary battery energy storage (BES) ${ }^{5}$ in the United States (BNEF 2020; Wood MacKenzie and ESA 2020). The U.S. energy storage market is expected to grow from an annual deployment of 523 megawatts in 2013 to 7.3 gigawatts in 2025 (Wood MacKenzie and ESA 2020; Wesoff 2020). Rapid growth in the U.S. passenger EV market is also projected to continue, and the deployment of commercial EVs is expected to gain momentum by 2030 (BNEF 2020). Annual passenger EV sales in the United States are forecasted to reach 1.1 million by 2025 , and 4.0 million annually by 2030 , which equates to 16 million units on U.S. roads by 2030 and 46 million by 2035 (BNEF 2020). LiBs are expected to continue to dominate the global market share for use in both mobile and stationary BES through 2035, and therefore lithium-ion BES (herein Li-BES or BES) is the focus of this report (BNEF 2020; Wood MacKenzie and ESA 2020; Mayyas, Steward, and Mann 2019).

As BES capacity increases in the United States, so will the volume of spent LiBs (Bade 2019). Estimates based on a 10-year lifetime assumption found that the volume of LiBs that have reached the end of their utility for EV applications could total two million units (four million metric tons) annually by 2040 in the United States (Richa et al. 2014; Ai and Borucki 2018). Retirements that are due to early failure (e.g., crashes and battery replacements), as well as BES deployment beyond earlier expectations, will increase these projections (Gibson 2019; Ai and Borucki 2018; Richa et al. 2014). There is currently no publicly available decommissioning ${ }^{6}$ or end-of-life $(\mathrm{EoL})^{7}$ projection for stationary BES systems, as LiBs have just recently started to gain market share in the primary energy storage market.

\footnotetext{
2 This report uses "lithium-ion batteries" to mean large-format LiBs for use in mobile and stationary battery energy storage systems (e.g., electric vehicles, solar plus storage).

3 This report uses "electric vehicle" (EV) to include all-EVs, hybrid EVs, and plug-in EVs.

${ }^{4}$ Bloomberg New Energy Finance's EV sale's analysis includes battery electric vehicles and plug-in electric vehicles (BNEF 2020).

${ }^{5}$ For the purposes of this report, unless otherwise specified, battery energy storage (BES) refers to both mobile (i.e., EV) and stationary BES systems (e.g., solar plus storage).

${ }^{6}$ This report uses "decommission" to mean mobile and stationary LiBs that have been removed from first-use system operation (e.g., EV use) but may still have reuse potential in secondary use applications (e.g., forklifts and stationary energy storage).

7 This report uses "end-of-life" to mean mobile and stationary LiBs that have been decommissioned because they have reached the end of their expected life and/or do not have reuse potential.
} 
As first-generation EV batteries reach EoL and the future of the LiB waste stream in the U.S. becomes more certain, industry stakeholders are left grappling with limited material management options. In theory, management options for retired LiBs from mobile and stationary BES systems include rebuilding for reuse ${ }^{8}$ (herein reuse), recycling-based resource recovery, storage, and disposal. However, the reuse of large-format LiBs is not at commercial scale and to date consists of only a handful of U.S.-led pilot projects. Further, the accessibility and cost of large-format $\mathrm{LiB}$ recycling is often overshadowed by cheaper and more accessible disposal options. As a result, anecdotal evidence suggests that today most decommissioned LiBs from EVs are landfilled or otherwise disposed of. In fact, less than $5 \%$ of LiBs from EVs in the United States are sent to recyclers (Steward et al. 2019; Salim et al. 2019; CPUC 2019; DTSC 2019d; NREL 2019b; Jacoby 2019; America Made 2019; Patel 2017).

As awareness of current practices grows, and the demand for critical LiB materials increases, U.S. industry stakeholders, regulators, and policymakers are starting to (1) consider solutions to drive and enable environmentally sustainable LiB management decisions and behaviors and (2) identify barriers to a circular economy for LiBs. Circular economy principles (Figure 1) attempt to transition from a "take-make-consume-dispose" linear economic system to a circular system that allows for the long life, high performance, and the reuse/recovery of products and materials (Ellen MacArthur Foundation 2016).

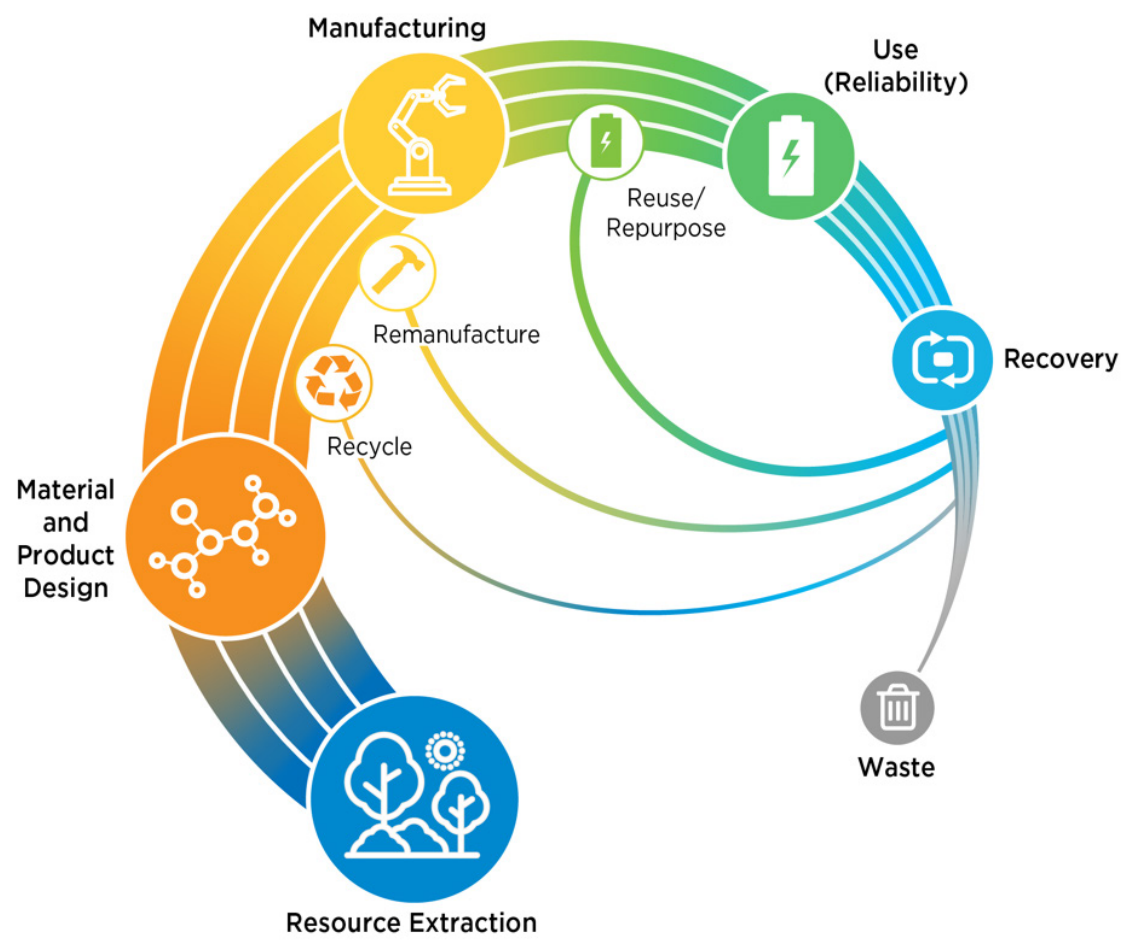

Figure 1. A circular economy for LiBs

\footnotetext{
${ }^{8}$ This report uses the terms "rebuild" and "rebuilt" to include various degrees of rebuilding, remanufacturing, refurbishing, repairing, or reconditioning large-format LiBs typically required for repurposing or reuse in a secondary use application.
} 
The reuse and recycling-based resource recovery (reuse/recovery) of LiBs can increase economic benefits for BES industry stakeholders, create new and expanded U.S. market opportunities, increase supply chain stability, reduce environmental impacts, and alleviate resource constraints. Manufacturers and system owners may obtain economic benefit from selling or donating LiBs for secondary use, or recycling LiBs for sale into commodity markets, or reuse in manufacturing. For example, retired EV LiBs could be reused for mobile and stationary BES applications that require-less frequent battery cycling (e.g., residential backup-power, forklifts) (Kelleher Environmental 2019; ReCell Center 2019a; Casals et al. 2019; Fan et al. 2020; Yang et al. 2019; Engel et al. 2019; CPUC 2019; Jiao 2019; Stringer and Ma 2018; Neubauer et al. 2015). ${ }^{9}$ Companies that engage in environmentally sustainable business practices such as reuse/recovery may in turn increase consumer trust and their overall competitiveness in the marketplace (Salim et al. 2019). Extracting additional services and revenue from LiBs also increases the total lifetime value of the BES system, and the costs can be shared by primary and secondary users. Incumbent stakeholders and new market entrants alike may expand or provide new services (e.g., reverse logistics, disassembly, and recycling) to meet reuse/recovery needs for LiBs. Further, the recovery of $\mathrm{LiB}$ materials could aid in domestic manufacturing opportunities. One estimate found the global Li-BES recycling market reached approximately $\$ 1.5$ billion in 2019 and is projected to grow to $\$ 18.1$ billion by 2030 (Uniyal 2020). Recycling LiBs can also divert valuable materials from landfills and reduce the need to mine for virgin materials, such as nickel, lithium, cobalt, iron, manganese, and graphite (ReCell 2019b; NREL 2019a; Jacoby 2019; Gaines 2018; Patel 2017; Elkind 2014). Recovery of these materials can also reduce waste, alleviate critical resource constraints, and lower dependence on foreign markets and imports.

Today there are technical, economic, and regulatory factors that inhibit a circular economy for LiBs in the United States. As a result, few manufacturers take into account design for extended product durability or design for reuse/recycling, and only a handful of U.S.-based companies work to reuse and/or recover LiB materials. Current technology, infrastructure, and processes associated with the reuse/recovery of LiBs are not optimized for efficient cost-effective reuse or recovery of valuable materials and the cost to reuse/recycle is often more than disposal. There is also limited publicly available research and market information available that could help inform investment decisions in the early stages of new and expanded BES market opportunities. In addition, the management of used LiBs also requires compliance with complex, variable, and at times, unclear federal, state, and local U.S. regulations.

BES system owners, and others involved in the management of retired and EoL LiBs have to consider the financial and legal liability associated with each management option. Today U.S. policy ${ }^{10}$ does not incentivize or mandate reuse or recycling of LiBs over disposal. Regulation in the U.S. may prohibit certain secondary use applications, and mandate specific requirements that carry civil and criminal penalties for violations. For example, interconnection, fire, building, and electrical regulations in the United States vary by jurisdiction and are at times ambiguous as to whether they apply to BES systems making it difficult to determine viable secondary use applications for LiBs. Moreover, LiBs destined for resource recovery are often regulated in the

\footnotetext{
${ }^{9}$ Laura Allerston, Aceleron Energy, teleconference, August 1, 2019

${ }^{10}$ We use "policy" in this report broadly to include not only federal, state, and local statutory and regulatory requirements but also government initiatives and goals.
} 
same manner as those being disposed, which does not provide a regulatory incentive to recycle LiBs. Used LiBs accumulated or stored before recycling or disposal, and those being recycled or disposed of may also be regulated as hazardous waste in the United States. Hazardous waste laws in the United States vary by jurisdiction, and mandate specific handling, storage, and transportation requirements. In addition, transporters of LiBs regulated as hazardous or universal waste are subject to U.S. Department of Transportation hazardous material regulations with specific packaging, documentation, and other transit-related requirements. Further, LiBs regulated as hazardous or universal waste that are shipped abroad may be subject to international treaty requirements and export regulations.

U.S. industry stakeholders, regulators, and policymakers are starting to consider and evaluate how policy ${ }^{11}$ may drive and enable a circular economy for LiBs, and also how policy and regulation can act as barrier to a desired outcome. Policies can incentivize innovation in battery design, as well as the development of LiB reuse/recycling services, business models, and processes. Government-funded R\&D and analysis, could enable private investment in the early stages of new and expanded BES market opportunities by providing answers to questions that could help alleviate market uncertainty. Clear and consistent federal, state, and local U.S. regulations related to the reuse and recovery of LiBs could also reduce regulatory uncertainty, liability concerns, and overall investor risk. Moreover, policies designed to encourage reuse and recycling instead of disposal may make the economics of early market investment more desirable.

We begin this report by summarizing drivers, barriers, and enablers to a circular economy for LiBs used in mobile and stationary BES systems in the United States. We then report on our analysis of federal, state, and local regulatory considerations that impact the reuse/recovery and disposal of LiBs, and potential civil and criminal liabilities associated with noncompliance. We conclude by highlighting state policies and initiatives in the United States that expressly address reuse/recovery and disposal of large-format LiBs.

Our results are based on legal and literature-based research. In addition, our results incorporate feedback and information we received from a series of interviews conducted through teleconference and email exchange with a diverse group of mobile and stationary BES experts, including academic and research organizations, industry associations, LiB manufacturers, LiB reuse/repair/recycling companies, consultants, as well as U.S. federal and state regulators, and policymakers. The questions used in each interview were tailored specifically to the industry stakeholders' areas of expertise. While this report addresses stationary and mobile LiBs, much of the information and experience with $\mathrm{LiB}$ reuse and EoL material management is derived from increased management of spent EV LiBs in the United States. Moreover, this report is limited to U.S. LiB-BES regulatory, policy, and market analysis.

This report is intended to inform decisionmakers, including those involved with policy design; it does not endorse any particular policy mechanism over another, nor does it assess all regulatory

\footnotetext{
${ }^{11}$ We use "policy" in this report broadly to include not only federal, state, and local statutory and regulatory requirements but also government initiatives and goals.
} 
requirements or the impacts that those requirements and policies may have on U.S. BES markets or related commodity markets. 


\section{Drivers, Barriers, and Enablers to a Circular Economy for LiBs}

Today, BES supply chains in the United States are characterized as linear economic models. Few BES manufacturers (e.g., Ford, General Motors, and Tesla) are investing in design for extended product durability, or design for reuse/recovery of LiBs, and only one U.S.-based manufacturer has implemented a takeback program to recover LiB materials ${ }^{12}$ (Evarts 2019; McCandless 2019; Kelleher Environmental 2019; Salim et al. 2019). ${ }^{13}$ The authors did not find any evidence that U.S. BES manufacturers are investing in design for reuse/recovery of LiBs, and investment in R\&D pilot projects for remanufacturing and reuse of spent EV batteries (e.g., EV charging stations, energy storage) are not yet at commercial scale (Warren 2020; Gerstein 2020). In addition, there are only a few U.S. third-party companies that recycle large-format LiBs, and only a few U.S. third-party companies that refurbish and/or resell used LiBs for secondary use (Kumagai 2021; Collins 2019; Kelleher Environmental 2019). ${ }^{14}$ Moreover, most companies that provide LiB recycling services do not process the batteries in the U.S. (Kumagai 2021). Instead, efforts to integrate circularity principles into BES supply chains has primarily been driven by federally funded government initiatives and pilot projects focused on battery recycling and EV batteries for secondary use applications (Kelleher Environmental 2019; ReCell 2019a).

In this section, we discuss drivers, barriers, and potential enablers to a circular economy for LiBs in the United States. In addition to doing literature-based research, we conducted interviews and interacted with BES experts to identify factors that may drive or act as a barrier to reuse/recovery of large-format LiBs in the United States. These stakeholder interactions also informed potential solutions that may enable reuse/recovery of large-format LiBs in the United States.

\subsection{Drivers}

Certain opportunities and benefits may drive a circular economy for LiBs in the United States. In this section, we discuss economic, environmental, and security opportunities and benefits that may drive material management decisions and behaviors that facilitate the integration of circularity principles into BES value and supply chains. Table 1 summarizes those drivers.

\footnotetext{
12 Tesla currently operates a takeback and recycling program for spent mobile and stationary LiBs serviced by a third-party recycler that also processes Tesla's battery manufacturing scrap. Tesla is investing in a fully closed-loop manufacturing operation in Nevada where it would take back and recycle spent EV, stationary storage, and solar application LiBs from customers (Kelleher Environmental 2019).

${ }^{13}$ Laura Allerston, Aceleron, teleconference, August 1, 2019

${ }^{14}$ Third-party companies that provide repair and reuse services or recycling for large-format LiB in the United States identified in this report include Retriev Technologies, Redwood Materials, OnToTechnology, Umicore, IT Asset Partners, Spiers New Technology, Sybesma’s Electronics, Battery Solutions, Battery M.D. Inc., Cleanlites Recycling, Inc., Li-Cycle, and Battery Resourcers (Kumagai 2021; Kelleher Environmental 2019).
} 
Table 1. Drivers of a Circular Economy for LiBs

\begin{tabular}{ll}
\hline $\begin{array}{l}\text { Economic Driver } \\
\text { (Section 2.1.1) }\end{array}$ & Potential Benefit \\
\hline Cost savings and increased profits & $\begin{array}{l}\text { Decrease manufacturing costs and achieve additional revenue } \\
\text { streams and tax benefits }\end{array}$ \\
\hline Enhanced competitiveness & $\begin{array}{l}\text { Increase a business's green or environmentally responsible } \\
\text { image and increase consumer trust }\end{array}$ \\
\hline $\begin{array}{l}\text { New and expanded market and } \\
\text { employment opportunities }\end{array}$ & $\begin{array}{l}\text { Provide opportunities for new and expanded markets, and } \\
\text { job creation }\end{array}$ \\
\hline $\begin{array}{l}\text { Environmental Driver } \\
\text { (Section 2.1.2) }\end{array}$ & Potential Benefit \\
\hline $\begin{array}{l}\text { Reduced negative } \\
\text { environmental impacts }\end{array}$ & $\begin{array}{l}\text { Reduce waste, the generation of greenhouse gases and other } \\
\text { environmental pollutants, and the total energy required to mine, } \\
\text { transport, refine and manufacture products }\end{array}$ \\
\hline Reduced resource constraints & $\begin{array}{l}\text { Conserve high-value materials, prevent resource constraints, } \\
\text { and reduce import demand for raw materials }\end{array}$ \\
\hline
\end{tabular}

\subsubsection{Economic Drivers}

New and expanded market opportunities, job creation as well as supply chain stability and resource security may drive federal, state, and local government investment in a circular economy for LiBs in the United States. Cost savings, increased profits, and enhanced competitiveness may drive private investment in product, service, and process innovation and the reuse/recovery of LiBs. This section discusses some of those economic drivers.

\subsubsection{Reuse}

Reuse of LiBs may create economic benefits for industry stakeholders and new and expanded market opportunities and job creation in the United States. Industry experts have observed that decommissioned EV LiBs often maintain as much as $80 \%$ of their original capacity and could be used in secondary mobile and stationary BES applications that require less-frequent battery cycling ${ }^{15}$ (Kelleher Environmental 2019; ReCell Center 2019a; Casals, Garcia, and Canal 2019; Fan et al. 2020; Yang, Gu, and Guo 2019; Engel, Hertzke, and Siccado 2019; CPUC 2019; Jiao 2019; Stringer and Ma 2018; Neubauer et al. 2015). ${ }^{16}$ Although it is largely in the R\&D and pilot project phase, LiBs from EVs may be good candidates for commercial and industry scale stationary BES systems, as well as residential, microgrid, and backup-power applications (Kelleher Environmental 2019; Engel, Hertzke, and Siccado 2019; Neubauer et al. 2015; Elkind et al. 2014). For example, Toyota and General Motors are exploring options to convert EV LiBs for use in stationary BES systems (Fan et al. 2020; Yang, Gu, and Guo 2020; Stringer and Ma 2018). In addition, LiBs from EVs may also be refurbished and reused in other automotive and battery applications that require less-frequent battery cycling (e.g., drones and forklifts)

\footnotetext{
${ }^{15}$ Large-format LiBs that have lost $20 \%$ of their original nameplate capacity no longer meet EV performance standards for traction control, acceleration, range, and regeneration capabilities (Pagliaro and Meneguzzo 2019; Saxena et al. 2015).

${ }^{16}$ Laura Allerston, Aceleron Energy, teleconference, August 1, 2019
} 
(Kelleher Environmental 2019). Extracting additional services and revenue from LiBs increases the total lifetime value of the BES system, and the costs could be shared by primary and secondary users (Neubauer et al. 2015).

Li-BES manufacturers and system owners may obtain economic benefits from selling or donating battery cells and modules for secondary use (Kelleher Environmental 2019). Although mostly theoretical at this time, system owners could sell spent LiB packs to generate revenue or donate LiB packs for charitable use and receive a tax credit. BES manufacturers may also takeback spent batteries from system owners to reuse or recycle and generate revenue or donate batteries for a tax benefit. BES manufacturers may also find it advantageous to sell or donate used LiBs to comply with voluntary industry standards or to enhance their corporate responsibility image (Salim et al. 2019). Companies that engage in environmentally sustainable business practices, such as reuse, may in turn increase consumer confidence in secondary market products, and their overall competitiveness in the marketplace (Salim et al. 2019).

The sale of used LiBs for repair and reuse in secondary applications may also present an opportunity for new and expanded BES markets and job creation in the United States. For instance, the sale of lower-cost used LiBs for stationary use could further increase stationary BES system deployment and may help enable access to traditionally underserved market participants such as low-and-moderate income communities. Also, industry stakeholders, such as auto dismantlers, manufacturers, repair shops and mechanics, could expand services to include repair and sale of LiB packs for reuse (Kelleher Environmental 2019). New companies may also be developed to provide reuse products and services (Kelleher Environmental 2019). These companies may provide a suite of services that could include collection, transport, disassembly of the battery pack; diagnostic and screening tests to identify battery chemistries; repair, refurbishment, reassembly, installation, and resale (Kelleher Environmental 2019).

\subsubsection{Recycling}

Recycling LiBs and manufacturing scrap could create economic benefits for industry stakeholders and new and expanded BES market opportunities and job creation in the United States (Jacoby 2019; Salim 2019; Gaines 2018; Elkind 2014). Recycling LiBs and manufacturing scrap could recover high-value materials that can be sold into commodity markets or be used to manufacture new LiBs (Salim et al. 2019; ReCell Center 2019b; NREL 2019a; Elkind 2014). Recycling LiBs and manufacturing scrap can recover valuable materials, such as cobalt, nickel, iron, graphite, lithium, and manganese from the cathode, electrolyte, black mass, and anode portions of the battery (ReCell 2019d; NREL 2019a; Jacoby 2019; Gaines 2018; Patel 2017; Elkind 2014). Recovered cobalt, nickel, manganese, or iron, for example, could be used to manufacture cathodes for LiB cells (Jacoby 2019; Gaines 2018; Patel 2017; Elkind 2014). The recovery of these materials could also provide an opportunity for growth in U.S. manufacturing sectors which could help meet domestic demand. One estimate found the global Li-BES recycling market reached approximately $\$ 1.5$ billion in 2019 and is projected to grow to $\$ 18.1$ billion by 2030 (Purushottam Uniyal 2020).

Li-BES manufacturers, system owners, third-party recyclers, and other industry stakeholders could gain an economic benefit from recycling LiBs. BES manufacturers could potentially lower manufacturing costs in the future by reusing recovered materials from customer warranty returns, manufacturing scrap, and other retired LiBs (ReCell Center 2019a; Gaines 2014). One estimate 
found that manufacturing costs for a new LiB cell are 5\%-30\% less when they use recycled cathode materials (ReCell Center 2019a). The reuse of recovered materials also reduces manufacturing costs, dependence on foreign imports, and could reduce the cost of LiBs on the primary market (Salim et al. 2019; ReCell Center 2019a, 2019b). System owners and third-party recyclers may also generate revenue by selling recovered materials into commodity markets (Salim et al. 2019; ReCell Center 2019b; Jacoby 2019; ReCell Center 2019d; NREL 2019a; Xu et al. 2018; Patel 2017; Elkind 2014). Similar to the reuse discussion above (Section 2.1.1.1), system owners and LiB manufacturers may find it advantageous to recycle LiBs to comply with voluntary industry standards or to enhance their corporate responsibility image (Salim et al. 2019; Wu et al. 2018). Companies that engage in environmentally sustainable business practices such as recycling may in turn increase consumer trust and their overall competitiveness in the marketplace (Salim et al. 2019; Xu et al. 2018).

Resource recovery of LiBs also presents an opportunity for new and expanded BES markets in the United States. Third-party recycling companies and lifecycle management companies could expand to offer services for LiBs, which could include handling and transporting LiBs for resource recovery. For example, Sybesma's Electronics, which is based in Michigan, expanded operations to offer EV LiB refurbishment, repair, and recycling services (Kelleher Environmental 2019). New market entrants such as Spiers New Technologies may also continue to emerge to provide recycling services and/or reverse-logistic services to manage retired $\mathrm{LiBs}$ (Kelleher Environmental 2019).

\subsubsection{Environmental Drivers}

Environmental drivers, such as reduced negative environmental impacts and reduced resource constraints may encourage federal, state, and local government investment as well as industry action and private investment in a circular economy for LiBs in the United States. This section discusses some of those environmental drivers.

Reuse/recovery of LiBs presents near-term and future environmental benefits. Secondary use of LiBs could reduce disposal of reusable products, while recycling-based resource recovery of LiBs could divert valuable materials, such as nickel and iron, from landfills (Salim et al. 2019; ReCell Center 2019a, 2019b; Argonne 2019; Jacoby 2019; NREL 2019a; Patel 2017; Elkind 2014). For example, in 2019, nickel recovered from manufacturing scrap and used nickel products ${ }^{17}$ accounted for $47 \%$ of the U.S. nickel supply used to meet domestic demand (USGS 2020a).

Moreover, the reuse/recovery of LiBs and manufacturing scrap could alleviate resource constraints and the demand on critical minerals, such as cobalt, graphite, lithium, and manganese in the United States. The Department of Interior classifies cobalt, graphite, lithium, and manganese as critical minerals, which are essential to U.S. economic and national security due to their necessity in product manufacturing, including use in LiBs for BES systems (Exec. Order

\footnotetext{
17 "Nickel in alloy form recovered from the processing of nickel wastes, including flue dust, grinding swarf, mill scale, and shot blast generated during the manufacturing of stainless steel; filter cakes, plating solutions, spent catalysts, spent nickel liquor, sludges, and all types of spent nickel-containing batteries" (USGS 2020a).
} 
No. 13817, 82 Fed. Reg. 60835 (2017); DOI 2018; Gaines, Richa, and Spangenberger 2018). ${ }^{18}$ The World Bank Group (2020) estimated global greenhouse gas mitigation commitments could increase demand for critical minerals used in stationary Li-BES to support renewable generation by $500 \%$ in 2050 . These critical minerals are subject to rising costs due to limited resources and supply chain disruption often caused by political instability in producing regions (Exec. Order No. 13817, 82 Fed. Reg. 60835 [2017]; DOI 2018; ReCell 2019b). ${ }^{19}$

Consideration: Experts expect a shortage of nickel for LiBs within 5-6 years if current trends persist (Mayyas, Steward, and Mann 2019; ReCell Center 2019c). Reuse/recovery of nickel from LiBs could help establish a robust domestic supply and decrease dependence on foreign imports, which may aid in guarding the United States against future supply chain disruptions.

Reuse/recovery of LiBs and manufacturing scrap could support sustainable resource governance by reducing the need to mine and export virgin minerals often found in countries with lessstringent environmental and human health regulations. For example, the Democratic Republic of the Congo maintains the largest cobalt reserves in the world with 3,600,000 metric tons (Mt), and it produced 100,000 Mt of refined cobalt in 2019 (USGS 2020b). In comparison, in 2019, the United States produced $500 \mathrm{Mt}$ of refined cobalt (USGS 2020b).

\subsection{Barriers}

Certain factors may inhibit a circular economy for LiBs in the United States. In this section, we identify technology, process, data, economic, and regulatory factors that may inhibit management decisions and behaviors that facilitate the integration of circularity principles into BES value and supply chains. Table 2 summarizes those barriers.

Table 2. Barriers to a Circular Economy for LiBs

\begin{tabular}{ll}
\hline Barrier & Description \\
\hline $\begin{array}{l}\text { Current technology, } \\
\text { infrastructure, } \\
\text { and processes } \\
\text { (Section 2.2.1) }\end{array}$ & $\begin{array}{l}\text { Technology, infrastructure, and processes that are not optimized for efficient, } \\
\text { cost-effective reconditioning for reuse and recovery of LiBs }\end{array}$ \\
\hline $\begin{array}{l}\text { Lack of critical } \\
\text { information and data } \\
\text { (Section 2.2.2) }\end{array}$ & $\begin{array}{l}\text { Limited information and data regarding: the value of, and markets for, reused } \\
\text { and recovered LiBs; the volume and composition of LiBs; the condition and } \\
\text { characteristics of used LiBs; quality, performance, reliability, safety, and } \\
\text { technical viability of reused and refurbished LiBs; refurbishment processes } \\
\text { and recycling technology; and infrastructure needs }\end{array}$ \\
\hline $\begin{array}{l}\text { Unclear, complex, } \\
\text { and varied laws, } \\
\text { regulations } \\
\text { (Section 2.2.3) }\end{array}$ & $\begin{array}{l}\text { Laws and regulations applicable to reuse/recovery of LiBs that are unclear, } \\
\text { complex, and vary by jurisdiction }\end{array}$ \\
\hline $\begin{array}{l}\text { Lack of economic } \\
\text { motivation } \\
\text { (Section 2.2.4) }\end{array}$ & $\begin{array}{l}\text { Limited economic motivation or incentive to enable collection, transport, and } \\
\text { reuse/recovery of LiBs, or to enable the design for durability, reuse, and } \\
\text { recycling }\end{array}$ \\
\hline
\end{tabular}

${ }^{18}$ Exec. Order No. 13817, 82 Fed. Reg. 60835 (2017)

${ }^{19}$ Exec. Order No. 13817, 82 Fed. Reg. 60835 (2017) 


\begin{tabular}{ll}
\hline Barrier & Description \\
\hline Low market confidence & Inadequate consumer confidence in reused and repaired LiBs to support \\
in reused and & reuse and repair-for-reuse secondary markets \\
repaired materials & \\
(Section 2.2.4) & \\
\hline
\end{tabular}

\subsubsection{Technology, Infrastructure, and Process Barriers}

Technology, product, and process innovation plays a critical role in efficiency, cost savings, increased profits, and enhanced competitiveness for any industry. Current technology, infrastructure, and processes associated with the reuse/recovery of LiBs are not optimized for efficient cost-effective reconditioning for reuse or recovery of valuable materials. As such, the accessibility and cost of disposal may be more desirable (Salim et al. 2019). This section discusses technology, infrastructure, and process barriers that may inhibit a circular economy for LiBs, and secondary BES market opportunities in the United States.

Today, there are many different battery chemistries and no standardized module or cell structure for LiBs (Harper et al. 2019). LiBs have different shapes, sizes, and material compositions, which may vary from manufacturer to manufacturer, and even across different models from the same manufacturer (Gaines, Richa, and Spangenberger 2018). The variability in LiB design and composition makes it difficult to design a standardized process for safety and reliability testing for secondary use applications. The variability in LiB design and composition also makes it difficult to automate disassembly and recycling processes, requiring costly manual pack removal, pack disassembly, module removal, and cell separation (CalEPA 2019; Harper et al. 2019). In addition, methods of joining battery packs could also impede reuse/recovery efficiencies, such as welding the pack shut rather than fastening the pack together with nuts and bolts (Gaines, Richa, and Spangenberger 2018). Some U.S. government-funded R\&D efforts are focused on the design of LiBs for easier reuse/recovery, but none of these efforts are at commercial scale.

There is limited infrastructure and no efficient processes in place in the United States to handle the projected volume of retired and EoL LiBs from EVs and stationary application. We identified only a few collection/sorting sites that could handle large-format LiBs and only one recycling facility in the United States (Kelleher Environmental 2019). Moreover, there is limited guidance and no standardized process for the safety and reliability of LiBs for secondary use applications, and there is no standardized or automated process to disassemble LiBs for resource recovery.

Current LiB recycling technology, such as hydrometallurgical (chemical) and pyrometallurgical (smelting) processes are not optimized for cost-effective recovery of high-purity materials at high recovery rates (Gaines, Richa, and Spangenberger 2018). Pyrometallurgical recycling of LiBs recovers some metals but leaves high-value metals such as lithium and aluminum in the slag, making them difficult to cost-effectively recover (Gaines, Richa, and Spangenberger 2018; ReCell 2019a). Hydrometallurgical recycling can recover high-value metals such as lithium and copper, but the extraction method requires costly reprocessing to reuse the recovered metals (Gaines 2018; ReCell 2019a; ReCell 2020). Some U.S. government-funded R\&D efforts are focused on advancing reuse/recovery technologies and processes, but none of these efforts are at commercial scale. 


\subsubsection{Information and Data Barriers}

Research and data play an important role in informing investment decisions in the early stages of new and expanded market opportunities, but publicly available LiB research and BES market information regarding retired LiBs in the United States is limited and variable. This section discusses information and data barriers that may inhibit a circular economy for LiBs and secondary BES market opportunities in the United States.

Publicly available information about the volume, timing, and condition of retired LiBs is limited and variable. The lifespan and average condition of LiBs when retired is largely theoretical because first-generation LiBs for EVs are just now reaching the end of their forecasted life expectancy, and LiBs for use in stationary BES systems are just now starting to dominate the primary market (Kelleher Environmental 2019; Gaines, Richa, and Spangenberger 2018; Ai and Borucki 2018; Neubauer et al. 2015; Richa et al. 2014). Varying life expectancy, remaining charge rate, and deployment assumptions among other metrics for mobile and stationary LiBs account for the wide range in life expectancy projections. Moreover, there is limited publicly available information and projects to demonstrate the quality, performance, safety, and technical viability of reused and refurbished LiBs which may impact consumer trust and confidence in the reuse of LiBs (Kelleher Environmental 2019; Gaines, Richa, and Spangenberger 2018; Ai and Borucki 2018; Neubauer et al. 2015; Richa et al. 2014).

Analysis of, and data on, the true costs of reconditioning LiBs for reuse and recovery of valuable materials is limited. Analyses to date have primarily focused on disassembly (e.g., pack removal, disassembly, module removal, and cell separation) and recycling processing costs, and these analyses do not account for infrastructure needs (e.g., collection centers and equipment), reverse logistics (e.g., sorting, handling, and transport), operating expenses, or regulatory compliance (Mayyas, Steward, and Mann 2019; Neubauer et al. 2015; Richa et al. 2014). The authors did not find any analysis of, or data on, the costs related to refurbishment and reuse of LiBs. There are also no analyses that take into account future innovation in reuse/recovery processes or advances in LiB technology (Mayyas, Steward, and Mann 2019).

Information about the value of and markets for repurposed $\mathrm{LiBs}$ and recovered $\mathrm{LiB}$ material is also limited. Data on the salvage value of and markets for used LiBs is limited, and the information that is available is highly variable because of uncertainties regarding the price for newer, more-efficient batteries, repurposing costs, and battery lifespan and degradation data for first-life and second-life applications (Kelleher Environmental 2019). Similarly, there is limited commodity market data for recovered LiBs that considers current $\mathrm{LiB}$ chemistries and designs, and no projections take into account changing battery chemistries or future reuse and recycling technology and process efficiencies (Mayyas, Steward, and Mann 2019; Salim et al. 2019; Kelleher Environmental 2019; Gaines 2018; Standridge and Corneal 2014; Richa et al. 2014). 


\subsubsection{Regulatory Barriers}

Federal, state, and local regulations play a critical role in consumer product safety and reliable electricity service. Regulations may also help ensure the safe handling, storage, treatment, ${ }^{20}$ transport, reuse, recycling, and disposal of LiBs. However, how state and local interconnection, fire, building, and electrical regulations apply to BES systems is often unclear. In addition, federal, state, and local laws and regulations mandate costly handling, storage, transport, and treatment requirements for recycling and disposal of LiBs, which carry civil and criminal penalties for noncompliance. Moreover, these federal, state, and local laws and regulations are complex, vary by jurisdiction, and are at times unclear as to how they apply to certain reuse and recovery processes for LiBs. This section highlights some regulatory barriers that may inhibit a circular economy for LiBs and secondary BES market opportunities in the United States.

\subsubsection{Reuse}

Unclear and variable state and local U.S. regulations may impact LiB reuse applications and investment in secondary BES markets (Section 3). Most interconnection, fire, building, and electrical regulations in the United States vary by jurisdiction. Moreover, these regulations often do not specifically address BES systems, and they are often ambiguous as to whether they apply (Twitchell 2019; Kaufman et al. 2011; NREL 2019a; IREC 2017). Only a few jurisdictions in the United States have taken steps to revise and clarify their interconnection regulations to address how they apply to BES systems (IREC 2017). Similarly, industry-led efforts to draft fire, building, and electrical model standards that specifically address repurposed LiBs are largely in the development phase (NFPA 2020; Cole and Conover 2016; NEC 2017; UL 2019). ${ }^{21}$ Beyond the analysis done for this report, we found no study that analyzes the impact that interconnection, fire, building, and electrical regulations have on the viability of grid-tied and off-grid secondary use applications for LiBs. The uncertainty and lack of guidance in BES system and large-format $\mathrm{LiB}$ regulations and standards make it difficult to determine viable secondary use applications for LiBs, which may stifle consumer confidence in secondary use products and overall investment in the reuse of LiBs.

\subsubsection{Recycling}

Complex, variable, and at times, unclear federal, state, and local U.S. regulations may impact resource recovery of valuable LiB materials (Section 4). Used LiBs accumulated or stored before recycling, and those being recycled may be regulated as solid waste and potentially hazardous waste in the same manner as LiBs accumulated or stored before disposal, and those being disposed of pursuant to the Resource Conservation and Recovery Act of 1976 (RCRA). ${ }^{22}$ RCRA solid waste laws in the U.S. vary by jurisdiction and they mandate specific handling, storage, transport, treatment, recycling, and disposal requirements that carry civil and criminal penalties

\footnotetext{
${ }^{20}$ Treatment means "any method, technique, or process, including neutralization, designed to change the physical, chemical, or biological character or composition of any hazardous waste so as to neutralize such waste, or so as to recover energy or material resources from the waste, or so as to render such waste non-hazardous, or less hazardous; safer to transport, store, or dispose of; or amenable for recovery, amenable for storage, or reduced in volume" (40 C.F.R. $\S 260.10)$.

${ }^{21}$ Ken Boyce, Underwriters Laboratory, email, May 17, 2019

2240 C.F.R. $\S \S 260-265,273$; Universal Waste Rule, 60 Fed. Reg. 25,492, 25,492 (May 11, 1995; to be codified at 40 C.F.R. Parts 9, 260, 261, 262, 264, 265, 266, 268, 270, and 273)
} 
for violations. Transporters of LiBs may also be subject to stringent U.S. Department of Transportation (DOT) hazardous materials regulations. Beyond the analysis done for this report, we found no study that comprehensively analyzes RCRA solid waste/hazardous waste and DOT requirements to handle, transport, store, treat, recycle and dispose of LiBs in the United States.

There is also evidence of confusion about whether a RCRA regulatory exclusion may apply to certain recovery processes for LiBs. ${ }^{23}$ For example, whether new recycling technologies such as cathode-to-cathode relithiation constitute reclamation and trigger RCRA regulation is a subject of debate. ${ }^{24}$ Unclear and variable regulation may create a level of risk and uncertainty that stifles investment in the recovery of $\mathrm{LiB}$ material. Moreover, if a RCRA regulatory exclusion does not apply to LiBs that are recycled, and they are regulated in the same manner as LiBs that are disposed of, there may be a lack of motivation to recycle LiBs until the economics of recycling become more competitive with disposal.

\subsubsection{Economic and Market Barriers}

Today there is limited economic motivation or incentive for private industry to invest in the reuse or recovery of LiBs. Similarly, there is a lack of consumer confidence in the secondary use of LiBs for mobile and stationary BES application. Moreover, the cost and accessibility of reuse and recycling options for $\mathrm{LiBs}$ is often outweighed by cheaper more accessible disposal options. This section discusses economic and market barriers that may inhibit a circular economy for LiBs and secondary BES market opportunities in the United States.

Economic, market, and regulatory uncertainty coupled with legal liability concerns may inhibit secondary BES market opportunities, the recovery of valuable LiB resources, and overall investment in BES products, processes, and services innovation. Today, technology, infrastructure, and processes associated with reuse/recovery of LiBs are limited and are not optimized for efficient cost-effective reconditioning for reuse or recovery of valuable materials (Salim et al. 2019; Gaines, Richa, and Spangenburger 2018). Safety and reliability testing for reuse is not streamlined, and disassembly and recovery processes are not automated or costeffective (CalEPA 2019; Harper et al. 2029). Further, there is limited data on the true costs of reconditioning $\mathrm{LiBs}$ for reuse, or on the true costs of recovering valuable LiB resources (Salim et al. 2019). Information about the value of and markets for repurposed LiBs and recovered LiB materials is also limited (Salim et al. 2019). Moreover, there is uncertainty about which regulations apply to the reuse of LiBs, and there is also a lack of guidance on the safe and reliable reuse of LiBs for secondary use application (Section 3) (Twitchell 2019; Kaufman et al. 2011; NREL 2019a; IREC 2017). Similarly, the handling, transportation, storage, and treatment requirements, which carry civil and criminal liability penalties for violations, are complex, variable, and at times unclear (Section 4). Federal, state, and local regulations may also manage used LiBs destined for resource recovery in the same manner as those being disposed of, which may inhibit recovery of valuable LiBs if the economics of disposal are more favorable (EPA 2019d). ${ }^{25}$ Moreover, we did not identify many U.S. federal, state, or local economic incentives or

\footnotetext{
${ }^{23}$ David Wagger, ISRI, email, August 3, 2020

${ }^{24}$ David Wagger, ISRI, email, August 3, 2020

2540 C.F.R. $\S \S 260-265,273$; Universal Waste Rule, 60 Fed. Reg. 25,492, 25,492 (May 11, 1995; to be codified at 40 C.F.R. Parts 9, 260, 261, 262, 264, 265, 266, 268, 270, and 273)
} 
policies that could help incentivize the reuse/recovery of LiBs, or early investment in new and expanded BES markets.

\subsection{Enablers}

Certain factors may enable a circular economy for LiBs in the United States. In this section, we discuss factors that may enable management decisions and behaviors that facilitate the reuse/recovery of LiBs. Table 3 summarizes those enablers.

Table 3. Potential Enablers to a Circular Economy for LiBs

\begin{tabular}{|c|c|}
\hline Enabler & Description \\
\hline $\begin{array}{l}\text { Research, } \\
\text { development, } \\
\text { and analysis } \\
\text { (Section } 2.3 .1 \text { ) }\end{array}$ & $\begin{array}{l}\text { The following could reduce uncertainty and investment risk, inform market } \\
\text { opportunities, and increase consumer confidence: } \\
\text { - R\&D and analysis regarding: } \\
\circ \text { The value of and markets for reused and recovered LiB materials } \\
\circ \text { The volume, condition, and composition of LiBs } \\
\circ \text { Battery design } \\
\circ \quad \text { Refurbishment processes and recycling technology } \\
\circ \quad \text { Infrastructure and service needs } \\
\text { - Techno-economic analysis } \\
\text { - Technical guidance }\end{array}$ \\
\hline $\begin{array}{l}\text { Publicly available } \\
\text { information and } \\
\text { information } \\
\text { exchange } \\
\text { (Section 2.3.2) }\end{array}$ & $\begin{array}{l}\text { Information availability and exchange-between manufacturers, system owners, } \\
\text { installers, operation and maintenance entities, third-party reuse/recycling } \\
\text { companies, logistics companies, landfill owners/operators, repair shops, } \\
\text { mechanics, and other BES supply chain actors-could reduce costs, market and } \\
\text { regulatory uncertainty and risk, and increase good faith relationships between } \\
\text { industry stakeholders }\end{array}$ \\
\hline $\begin{array}{l}\text { Economic } \\
\text { incentives } \\
\text { (Section 2.3.3) }\end{array}$ & $\begin{array}{l}\text { Both (1) incentives given to promote the collection, transport, and reuse/recovery } \\
\text { of LiBs and (2) LiB design for durability and reuse/recovery could encourage } \\
\text { innovation and private investment by making the economics of early investment } \\
\text { more desirable }\end{array}$ \\
\hline $\begin{array}{l}\text { Regulation } \\
\text { and policy } \\
\text { (Section 2.3.4) }\end{array}$ & $\begin{array}{l}\text { Federal and state policies could require or incentivize the collection and } \\
\text { reuse/recovery of LiBs and manufacturing scrap, and/or restrict disposal. Clearly } \\
\text { defined regulatory requirements could reduce uncertainty and risk associated with } \\
\text { LiB reuse/recovery activities (e.g., regulatory requirements under RCRA). In the } \\
\text { absence of regulation, global and national voluntary industry standards (e.g., UL } \\
\text { 1974) and goals (e.g., durable, standardized LiB design) could enhance a } \\
\text { company's competitiveness and provide consumer confidence in secondary } \\
\text { market goods }\end{array}$ \\
\hline
\end{tabular}

\subsubsection{Research, Development, and Analysis Enablers}

R\&D and analysis play a critical role in the design of durable, more easily reused, and recycled LiBs, as well as the development of LiB reuse/recycling services, business models, and processes. Government-funded R\&D and analysis could enable private investment in the early stages of new and expanded BES market opportunities by providing answers to questions that could help alleviate market uncertainty. This section discusses R\&D and analysis factors that may enable reuse/recovery of LiBs and secondary BES market opportunities in the United States. 


\subsubsection{Reuse}

R\&D and analysis regarding the expected volume and timing of spent LiBs could provide valuable insight for investment in new and expanded BES markets in the United States (Salim et al. 2019; Neubauer et al. 2015; Bowler 2014; Richa et al. 2014). Vehicle diagnostic and degradation data, as well as improved methods of monitoring batteries in the field could aid life expectancy projections (Harper et al. 2019; Neubauer et al. 2015). Accurate data regarding EV battery life expectancy and average condition (e.g., remaining charge, state of health) when batteries are retired could inform supply projections and help identify viable secondary use applications. Moreover, R\&D, analysis, and demonstration projects on the quality, performance, safety, and technical viability of reused and refurbished LiBs may increase consumer trust and confidence in the reuse of LiBs (Kelleher Environmental 2019; Gaines, Richa, and Spangenberger 2018; Ai and Borucki 2018; Neubauer et al. 2015; Richa et al. 2014).

R\&D and analysis focused on battery standardization and design could enable easier reuse (including remanufacturing and repair). Innovation in cell design and material composition could improve reconditioning and remanufacturing process efficiencies but should be balanced with concerns about product performance and efficient manufacturing (Harper et al. 2019; Gaines, Richa, and Spangenberger 2018). For maximum efficiency, the reconditioning process could be tailored to a specific cathode chemistry (Harper et al. 2019). Also, battery standardization and design changes, such as Aceleron's ${ }^{26}$ LiB compression technology could enable disassembly and process efficiencies for battery pack safety and reliability testing, which could in turn improve the economics of secondary use applications and consumer confidence in reused products (Harper et al. 2019; CalEPA 2019; Gaines, Richa, and Spangenberger 2018). ${ }^{27}$

Example: The U.S. Department of Energy (DOE) has funded the ReCell Center, which focuses on R\&D LiB recycling technology and sustainable battery design. Specifically, the ReCell Center's work looks at alternatives to welding a battery pack together for easier disassembly for repair and reuse.

Analyses that provide comprehensive estimates of (1) reconditioning costs and (2) the resale value of $\mathrm{LiB}$ materials could provide important insight to investors. Reconditioning cost estimates for LiB include the costs of sorting, grading, safety and reliability testing, reverse logistic activities, and regulatory compliance. Resale value estimates for different markets, combined with a comprehensive reconditioning cost estimate could inform private investment decisions in secondary BES market opportunities, and could inform the overall value of LiBs on the primary market (Harper et al. 2019; Mayyas, Steward, and Mann 2019; Salim et al. 2019; Neubauer et al. 2015).

Analysis and technical guidance about the reuse of LiBs could increase the value of the battery and reduce liability and secondary market uncertainty. Technical guidance could improve the safety and reliability of repurposed LiBs, which can extend the useful life of the battery, improve consumer confidence in repurposed products, and drive secondary market demand (Salim et al. 2019; Bowler 2014). In addition, analysis and guidance about regulatory compliance regarding

${ }^{26}$ Aceleron is a UK company that develops advanced LiB technology.

${ }^{27}$ Laura Allerston, Aceleron Energy, teleconference, August 1, 2019 
refurbishment processes and the reuse of LiBs could inform market opportunities and the viability of grid-tied secondary use applications and reduce investor risk and uncertainty.

Consideration: The Underwriters Laboratories (UL) 1974 Standard for Evaluation of Repurposing Batteries is the first standard that provides guidance on sorting and grading battery packs, modules and cells and electrochemical capacities that were originally configured and used for other purposes (UL 2019a). However, this standard does not include guidance on the reuse of remanufactured, refurbished, or rebuilt batteries (UL 2019a).

\subsubsection{Recycling}

R\&D and analysis focused on the volume of, value of, and markets for recovered LiBs could help alleviate market uncertainty and investor risk in recycling LiBs in the United States. Research that identifies the current and projected volume of retired LiBs in the United States provides insight on the potential supply of recovered materials, while R\&D and analysis focused on the value of and markets for recovered materials informs the potential demand and expected profits (Salim et al. 2019; Gaines 2018; Standridge and Corneal 2014).

Techno-economic analysis that compares recycling methods informs the most cost-effective means of recycling and recycling technology needs (Kelleher Environmental 2019; Gaines 2018; Standridge and Corneal 2014; Richa et al. 2013). Studying the performance of battery materials under diverse conditions, as well as environmental and economic impacts on various stages of the LiB lifecycle, could also provide insight on the impacts of different recycling processes (ReCell 2019b, 2019d; Gaines 2018). Evaluating the environmental and economic impact of recycling technologies could guide $\mathrm{R} \& \mathrm{D}$ needs and ensure maximized benefits and minimized tradeoffs. Also, techno-economic analysis could inform the true costs of recycling and could take into account not only disassembly (e.g., pack removal, module removal, and cell separation) and processing costs but also infrastructure needs (e.g., collection centers and equipment), reverse logistics (e.g., sorting, handling, and transport), operating expenses, and regulatory compliance costs (Mayyas, Steward, and Mann 2019; Salim et al. 2019; Kelleher Environmental 2019; Gaines 2018; Standridge and Corneal 2014; Richa et al. 2014).

Example: The ReCell Center's supply chain analysis and EverBatt model provide estimates of the economic and environmental impacts of closed-loop LiB recycling and the impacts recycling could have on primary manufacturing, supply, and demand (ReCell 2020).

R\&D and analysis focused on improvements to recycling technology could encourage innovation, improve the overall economics of recycling, and make private investment more desirable (Salim et al. 2019; Kelleher Environmental 2019; Gaines, Richa, and Spangenberger 2018). R\&D focused on optimizing cost-effective recovery of high-purity materials at high recovery rates will make the economics of recycling more attractive and more competitive with disposal. The ReCell Center's work on direct cathode recycling looks to recover higher value materials, such as lithium, through a process that does not require reprocessing before reuse in LiB remanufacturing. Moreover, R\&D focused on the recovery of critical material from not only the cathode but also electrolyte, black mass, and anode portions of the battery will provide an alternate domestic source for production and will reduce U.S. reliance on foreign resources. For example, the ReCell Center's research looks to recover lithium from the electrolyte component 
of battery materials (ReCell 2019b). R\&D for recycling technology might also consider how new technology designs may be regulated. U.S. regulation is often specific to the recycling processes used and the materials being recycled; as a result, certain recycling processes are regulated more stringently than others. Regulatory analysis could inform how new recycling technology and processes may be regulated, and it could ultimately inform the true cost-effectiveness and overall viability of a particular recycling technology.

R\&D and analysis focused on recycling infrastructure needs and reverse logistic services and operations could encourage innovation, improve the overall economics of recycling, and make private investment more desirable. Analysis of current recycling infrastructure and compatibility with handling, storage, transport, and recycling LiBs could inform infrastructure needs, as well as reverse logistic services and operation needs. In addition, geospatial analysis could inform the placement of additional operations and services, such as collection sites and recycling facilities, to increase reverse logistic efficiencies. For example, DOE's Lithium-Ion Battery Recycling Prize provides an incentive to industry to create innovative services and processes to enable costeffective recycling of LiBs in the United States. Specifically, the competition challenges industry to create scalable processes that could profitably capture $90 \%$ of all discarded or spent LiBs in the United States (NREL 2019c). Potential prize topics include systems to incentivize and encourage collection, effective sorting and separating technologies, methods for safe storage and transport, and solutions to lower costs associated with reverse logistics (DOE 2019a; DOE 2019b).

Similar to the reuse discussion in the previous section (Section 2.3.1.1), R\&D focused on battery design standardization could enable recycling efficiencies. Innovation in cell design and material composition, as well as pack design, can enable easier disassembly. Battery standardization could also lead to automated recycling processes for more efficient pack removal, disassembly, module removal, and cell separation (Harper et al. 2019; Gaines, Richa, and Spangenberger 2018). ${ }^{28}$

Analysis focused on future LiB designs could provide valuable market insight for recycling LiBs. Understanding potential changes in battery chemistry and design (e.g., shifting battery cathode chemistries from high cobalt to low cobalt, high nickel content) are important to recycling efforts because they have a meaningful impact on the supply and demand of specified materials and the value of those materials in commodity markets (Mayyas, Steward, and Mann 2019; Harper et al. 2019; Richa et al. 2014). Changes in battery design and chemistry may also impact life expectancy analyses and the volume and timing at which LiBs enter the recycling supply chain. Similarly, understanding the evolution of $\mathrm{LiB}$ chemistries and designs could also inform recycling technology needs. For example, most recyclers today focus on recovering critical materials, which are mainly found in the cathode (Mayyas, Steward, and Mann 2019). However, changes in LiB chemistries, including anode composition, may inform recycling technology needs and drive a desire to recover materials from not only the cathode but also the anode and other battery pack components.

${ }^{28}$ Laura Allerston, Aceleron Energy, teleconference, August 1, 2019 
Similar to the discussion above for reuse (Section 2.3.1.1), analysis and technical guidance for recycling LiBs could (1) increase safe handling, transport, and storage of LiBs and (2) reduce liability concerns. In addition, analysis and guidance on federal, state, and local regulation could reduce uncertainty and risk associated with noncompliance.

\subsubsection{Information Availability and Exchange Enablers}

Information availability and exchange can play an important role in facilitating reuse/recovery of LiBs. Increasing the amount of information available to - and the exchange of information among-BES industry stakeholders regarding LiBs may enable reuse/recovery and new and expanded market opportunities in the United States. This section discusses information availability and exchange factors that may enable reuse/recovery of LiBs in the United States.

Reliable information about the composition, chemical makeup, and the concentration of materials in a given LiB model could reduce the costs and liabilities associated with reuse/recovery efforts (Salim et al. 2019; ReCell 2019a; ReCell 2019d; Gaines, Richa, and Spangenberger 2018; Standridge and Corneal 2014). Labeling requirements related to the specific chemical makeup of the battery could enable information exchange between manufacturers and LiB material management stakeholders and secondary market entrepreneurs that can inform the safe handling, transport, storage, and reuse/recovery of spent LiBs (Salim et al. 2019; Gaines, Richa, and Spangenberger 2018; Standridge and Corneal 2014). Such information exchange could also act as a stopgap measure for manufacturers that go out of business before a LiB is retired or decommissioned (Salim et al. 2019). And such shared knowledge could also eliminate the need for expensive diagnostic screening required for the safe disassembly of batteries for reuse/recovery (Salim et al. 2019; Gaines, Richa, and Spangenberger 2018; Standridge and Corneal 2014). In addition, transparent information exchange can strengthen relationships between different BES industry stakeholders and help ensure the safe handling of used LiBs (Salim et al. 2019; Gaines, Richa, and Spangenberger 2018).

\subsubsection{Economic and Market Enablers}

Government subsidies, grants, or awards can enable private industry investment in new and expanded BES market opportunities by reducing financial risk and making early investment more desirable. This section discusses some economic and market enablers that may support reuse/recovery of LiBs and secondary BES market opportunities in the United States.

Federal and state government economic incentives could enable private industry investment in reuse/recovery BES markets by making the economics of early market investment more desirable (Salim et al. 2019). Federal and state government subsidies, grants, or awards to support new reuse/recovery companies or incumbent industry providers seeking to expand their services to include direct reuse/recycling operations or reverse logistic services could help encourage private investment by reducing investment risk (ReCell Center 2019a, 2019b; UL 2019a). Similarly, direct federal or state funding for R\&D could encourage innovation in the design for more durable, standardized LiBs, which in turn could increase reuse applications, secondary market opportunities, and recycling efficiencies (Gerstin 2020; Aceleron Energy n.d.; Calma 2019; Kelleher Environmental 2019). Business or tax incentives for R\&D and analysis as well as reuse/recycling companies could help industry stakeholders overcome current secondary market investment and resource recovery uncertainties (Salim et al. 2019). 


\subsubsection{Regulatory and Policy Enablers}

Federal, state, and local laws and regulations play a critical role in consumer product safety and reliable electricity service. Laws and regulations may also help ensure the safe handling, storage, treatment, transport, reuse/recovery, and disposal of LiBs. Policy could also drive and enable a circular economy for LiBs. Industry standards, in the absence of regulation, can also provide guidance for environmentally sustainable management decisions and behaviors for LiBs. This section discusses some regulatory and policy factors that may support reuse/recovery of LiBs and secondary BES market opportunities in the United States.

\subsubsection{Reuse}

Clear and consistent federal, state, and local U.S. regulations related to the reuse of LiBs could reduce regulatory uncertainty, liability concerns, and overall investor risk. Interconnection, fire, building, and electrical regulations that specifically address BES systems could enable safe and reliable installation of LiBs, help identify viable secondary use applications for LiBs, and increase consumer confidence in the reuse of LiBs (Twitchell 2019; Kaufman et al. 2011; NREL 2019a; IREC 2017). ${ }^{29}$ In addition, more consistent regulations across U.S. jurisdictions could reduce both (1) the regulatory complexity associated with compliance and (2) the liability and its associated costs.

Policies that mandate or incentivize reuse of LiBs could enable a circular economy for Li-BES. Federal and state regulations that prohibit disposal of LiBs, provide an exemption from stringent regulation for the reuse of $\mathrm{LiBs}$, that require reuse of LiBs, or incentivize reuse could enable sustainable management decisions and behaviors, and they could make early investment in reuse of LiBs more desirable. For example, North Carolina and California have passed laws to study and recommend policy to encourage the reuse of LiBs for stationary BES systems and EVs respectively (Section 5).

Finally, industry standards could provide guidance for the reuse of LiBs in the absence of regulation. For example, UL's 1974 Standard discusses techniques to sort and grade battery packs, modules and cells, and electrochemical capacitors originally used for other purposes (e.g., $\mathrm{EV}$ propulsion) to determine their viability for a repurposed use application such as a stationary BES system (UL 2019a). UL's standard, and similar standards could provide reliability and safety guidance for the installation of repurposed LiBs and improve consumer confidence in secondary use products.

\subsubsection{Recycling}

Clear and consistent federal, state, and local U.S. laws and regulations related to recycling-based resource recovery of LiBs could reduce uncertainty, liability concerns, and overall investor risk. For example, clarity and guidance on how RCRA solid and hazardous waste regulations apply to certain LiB recovery processes could (1) reduce regulatory uncertainty and liability concerns, and (2) inform R\&D for recycling technologies. Similarly, guidance on other regulatory schemes such as U.S. Department of Transportation regulations and their applicability to spent LiBs could inform the true costs of recycling LiBs. In addition, consistent regulations across U.S.

\footnotetext{
${ }^{29}$ Ken Boyce, Underwriters Laboratory, email, May 17, 2019
} 
jurisdictions could reduce both (1) the regulatory complexity associated with compliance and (2) the legal liability and its associated costs by reducing uncertainty related to the applicability of regulations to LiBs being recycled across different jurisdictions.

Similar to the reuse discussion in the previous section (Section 2.3.4.1), policies that mandate or incentivize recycling could also enable a circular economy for LiBs. For example, certain materials such as lead-acid batteries are subject to less-stringent RCRA regulation when recycled. Specifically, "persons who generate, transport, regenerate, collect, and store spent leadacid batteries before reclamation, but do not perform the actual reclamation," are excluded from RCRA hazardous waste regulations and are regulated pursuant to alternative regulatory controls that have less-stringent requirements. ${ }^{30} \mathrm{~A}$ similar exclusion from RCRA regulation for LiBs could encourage recycling LiBs over disposal.

In the absence of regulation, voluntary industry standards and industry-led initiatives may also encourage environmentally sustainable management decisions and behaviors for EoL LiBs. For example, a voluntary industry standard similar to NSF/ANSI 457 Sustainable Leadership Standard for Photovoltaic Modules and Photovoltaic Inverters could encourage LiB recycling in the United States. NSF/ANSI 457 establishes certification requirements that are focused on sustainable performance criteria for PV modules and inverters that include EoL management and design for recycling, and similar criteria could be developed for LiBs. Comparably, industry-led initiatives such as the Solar Energy Industries Association's (SEIA) National PV Recycling Program could be established for LiB recycling. SEIA's National PV Recycling Program aggregates services of recycling vendors and $\mathrm{PV}$ manufacturers to form a network of preferred partners that can cost-effectively recycle EoL PV modules (SEIA 2019). Industry-led initiatives such as SEIA's National PV Recycling Program could enable recycling of LiBs by making it easier for stakeholders to find a company to responsibly manage their decommissioned LiBs.

3040 C.F.R. $\S 266.80$ 


\section{Regulatory Considerations for the Reuse of LiBs}

In this section, we discuss state and local regulations that may impact the installation and interconnection of repurposed LiBs. In this section, we also discuss known voluntary industry certification standards for the reuse of LiBs for secondary use application. Table 4 summarizes those regulations and standards.

Table 4. Regulatory Considerations for the Reuse of LiBs

\begin{tabular}{ll}
\hline $\begin{array}{l}\text { Regulatory } \\
\text { Consideration }\end{array}$ & Description \\
\hline $\begin{array}{l}\text { Interconnection } \\
\text { regulations } \\
\text { (Section 3.1) }\end{array}$ & $\begin{array}{l}\text { State and local regulations that govern how BES systems connect to the } \\
\text { electric grid, which may impact the reuse of LiBs in certain grid-tied } \\
\text { applications }\end{array}$ \\
\hline $\begin{array}{l}\text { Fire and building } \\
\text { regulations } \\
\text { (Section 3.2) }\end{array}$ & $\begin{array}{l}\text { State and local regulations that govern the design, materials, and quality of } \\
\text { buildings and structures that house or connect to stationary BES systems, } \\
\text { which may impact the reuse of LiBs in certain grid-tied and off-grid } \\
\text { applications }\end{array}$ \\
\hline $\begin{array}{l}\text { Electrical regulations } \\
\text { (Section 3.3) }\end{array}$ & $\begin{array}{l}\text { State and local regulations that govern electrical safety, design, installation, } \\
\text { and inspection of BES systems and LiBs, which may impact the reuse of } \\
\text { LiBs in certain grid-tied and off-grid applications }\end{array}$ \\
\hline $\begin{array}{l}\text { Industry certification } \\
\text { standards } \\
\text { (Section 3.4) }\end{array}$ & $\begin{array}{l}\text { Voluntary industry standards that provide safety and reliability guidance for } \\
\text { the reuse of LiBs for secondary use installations }\end{array}$ \\
\hline
\end{tabular}

\subsection{Interconnection Regulations}

Battery energy stakeholders may want to consider state and local interconnection regulations that impact the reuse of LiBs in certain grid-tied applications. Jurisdictional interconnection regulations consist of legal requirements and procedures that govern how electric utilities, independent power producers, and consumers connect BES systems to the electric grid (CESA 2017). Interconnection requirements regulate the design, materials, and quality of electrical components required for grid-tied applications (CESA 2017).

Interconnection regulations are complex and vary by jurisdiction (e.g., locality by locality and state by state) (CESA 2017). Most interconnection regulations fall under the jurisdiction of state public utility commissions, but cities with municipal utilities may also influence interconnection regulations in their jurisdiction (CESA 2017; Ardani et al. 2015). In developing interconnection regulations, most jurisdictions in the United States have adopted, as a regulatory requirement, the Institute of Electrical and Electronics Engineers (IEEE) equipment standards, which reference and may be used in conjunction with UL testing standards - both of which are international voluntary industry standards (DOE 2011).

Interconnection regulations were not developed with BES systems in mind, and most U.S. state and local regulations do not explicitly include BES systems (Kaufman et al. 2011; Peterson 2018; CAISO 2014). Historically, state and local interconnection regulations were based on a narrow definition of generating facilities (e.g., power plants) and were designed to process requests to connect energy generation facilities to the electric grid (Kaufman et al. 2011; Peterson 2018; CAISO 2014). Stationary BES systems have the capacity to act as energy 
generators; however, unlike traditional generating facilities, BES systems can also act as negative generators (i.e., load) and can easily switch between generation and load functions (Kaufman et al. 2011; Peterson 2018; CAISO 2014). Because BES systems do not fit neatly into a traditional definition of a generating facility, the applicability of state and local interconnection regulations to BES systems is ambiguous (Kaufman et al. 2011; Peterson 2018; CAISO 2014). Although industry model interconnection standards have evolved in recent years to incorporate BES systems, most state and local jurisdictions have not yet adopted these model standards as regulatory requirements. Accordingly, state and local interconnection regulations, which do not specifically address stationary BES as well as the variability of regulations by jurisdiction, may create a level of uncertainty that impacts the reuse of LiBs for grid-tied applications (Twitchell 2019; Kaufman et al. 2011; Peterson 2018; NREL 2019a; IREC 2017).

Consideration: Some states-such as California and New York-are revising their regulations to ensure interconnection requirements specifically apply to BES systems. For example, in 2016, the California Public Utilities Commission set forth new rules clarifying how existing interconnection rules apply to energy storage and identified steps related to an expedited interconnection process for nonenergy exporting storage (IREC 2017).

\subsection{Fire and Building Regulations}

Battery energy stakeholders may want to consider state and local fire and building regulations that impact the reuse of LiBs in certain grid-tied and off-grid applications. Fire and building regulations are jurisdictional requirements that incorporate UL model testing standards used to grade and classify the fire resistance of buildings and structures which house or connect to stationary BES and rooftop electrical installations (e.g., stationary LiBs connected to rooftop PV systems) (NFPA 5000; IBC 2012).

Fire and building regulations are complex and vary by jurisdiction (e.g., locality by locality and state by state). Though fire regulations are not uniform across the United States, 42 states have adopted some version of the International Code Council's (ICC) International Fire Code, which is a voluntary industry standard, the purpose of which is to reduce the possibility of fire and mitigate fire damage to building structures (CESA 2017). In addition, all 50 states and all U.S. territories have adopted, as a regulation requirement, some version of the ICC's International Building Code (IBC) — an international voluntary industry standard that promotes safe building practices to provide safeguards from hazards associated with the built environment (ICC 2018).

Fire and building regulations were not developed with BES systems in mind, and most U.S. state and local regulations do not explicitly address BES systems (NFPA 2020; Cole and Conover 2016). ${ }^{31}$ To date, industry drafted model fire and building standards are evolving to specifically address BES systems (NFPA 2020; Cole and Conover 2016). ${ }^{32}$ For example, in 2020, NFPA published Standard 855, which specifically addresses fire hazards and spacing requirements for stationary BES systems (NFPA 855 Standard; NFPA 2020). ${ }^{33}$ However, most U.S. jurisdictions

\footnotetext{
${ }^{31}$ Ken Boyce, Underwriters Laboratory, email, May 17, 2019
}

32 Ken Boyce, Underwriters Laboratory, email, May 17, 2019 
have not integrated newer model standards that specifically address BES into their current fire and building regulations (Cole and Conover 2016; ESA 2018). Accordingly, the uncertainty regarding the applicability of fire and building regulations to BES system installation, as well as the variability of regulations by jurisdiction, may impact the reuse of LiBs for grid-tied and offgrid applications (NFPA 2020; Cole and Conover 2016). ${ }^{34}$

\subsection{Electrical Regulations}

Battery energy stakeholders may want to consider state and local electrical regulations that impact the reuse of LiBs in certain grid-tied and off-grid applications. Electrical regulations are jurisdictional requirements that govern BES system electrical components for grid-tied and offgrid applications (CESA 2017).

Electrical regulations are complex and vary by jurisdiction (e.g., locality by locality and state by state). Electrical regulations contain provisions that govern electrical equipment, including installation requirements. For example, electrical regulations may require the installation of certain equipment necessary to protect installers or first responders from electrical shock (CESA 2017). Though electrical regulations are not uniform across the United States, 46 states have adopted, as a regulatory requirement, some version of the National Fire Protection Association's (NFPA) National Electrical Code (NEC), which provides electrical installation requirements to minimize risks associated with the use of electricity. Some states leave the adoption of electrical regulations to local jurisdictions and have not adopted electrical regulations on a statewide level (CESA 2017).

Electrical regulations were not traditionally developed with BES systems in mind, and many state and local regulations do not explicitly include BES systems, or are not applicable to all BES systems (NEC 2017). To date, industry drafted model electrical codes are evolving to specifically address BES systems (NEC 2017; UL 2019b). For example, in 2017, NFPA published Article 706 to specifically address electrical safety standards of permanently installed BES systems (NEC 2017; UL 2019b). However, many U.S. jurisdictions have not integrated model electrical standards that specifically address BES into their current electrical regulations (NEC 2017). Accordingly, uncertainty regarding the applicability of U.S. electrical regulations to BES system installation, as well as the variability of regulations by jurisdiction, may impact the reuse of LiBs for certain grid-tied and off-grid applications.

\subsection{Industry Certification Standards}

Battery energy stakeholders may want to consider BES-specific voluntary industry standards, which could provide guidance for the reuse of LiBs in secondary use applications. Voluntary industry standards are developed by international organizations, such as UL and NFPA, to provide guidance on the safe and reliable design, installation, and use of products. State and local governments may adopt industry standards as regulatory requirements or as a best practice for industry guidance. Companies may also proactively seek a certification, which may in turn enhance consumer trust and confidence in the company or product and ultimately give the certified company a competitive advantage.

\footnotetext{
${ }^{34}$ Ken Boyce, Underwriters Laboratory, email, May 17, 2019
} 
Although industry-drafted model codes and standards have evolved to address BES generally, we found only one voluntary industry standard specific to the reuse of large-format LiBs: UL's 1974 Standard (UL 2019a). It addresses the safety and reliability of repurposed batteries, which may impact the secondary use of LiBs in grid-tied BES systems. Specifically, although the UL 1974 Standard does not produce a pass/fail result, the standard discusses techniques to sort and grade battery packs, modules and cells, and electrochemical capacitors originally intended for other purposes (e.g., EV propulsion) to determine their viability for a repurposed use application such as a stationary BES system (UL 2019a). In August 2019, 4R Energy Corporation ${ }^{35}$ became the first organization certified to the UL 1974 Standard to determine the viability of EV batteries for secondary use in a stationary BES system (UL 2019c).

${ }_{35}^{3} 4 \mathrm{R}$ Energy Corporation is a joint venture of Nissan and Sumitomo that is focused on the reuse of EV batteries for stationary BES systems (UL 2019c). 


\section{Statutory and Regulatory Considerations for the Reuse, Recycling, and Disposal of LiBs}

In this section, we discuss solid waste, hazardous waste, and universal waste statutory and regulatory requirements that may apply to reuse, recycling, and disposal of LiBs. This section also discusses hazardous material domestic transport regulations and hazardous waste export regulations that may apply to LiBs transported for reuse, resource recovery, or disposal. Table 5 summarizes those regulations.

Table 5. Statutory and Regulatory Considerations for the Reuse, Recycling, and Disposal of LiBs

\begin{tabular}{|c|c|c|}
\hline $\begin{array}{l}\text { Regulatory } \\
\text { Consideration }\end{array}$ & Description & Application \\
\hline $\begin{array}{l}\text { Solid waste law and } \\
\text { regulations } \\
\text { (Section 4.1) }\end{array}$ & $\begin{array}{l}\text { Mandatory requirements that vary across jurisdictions, } \\
\text { which govern the generation, handling, storage, treatment, } \\
\text { transport, recycling, and disposal of non-hazardous solid wastes, } \\
\text { which may include large-format LiBs accumulated or stored } \\
\text { before recycling or disposal, and those being recycled or } \\
\text { disposed of }\end{array}$ & $\begin{array}{l}\text { Recycle, } \\
\text { disposal }\end{array}$ \\
\hline $\begin{array}{l}\text { Hazardous waste } \\
\text { law and regulations } \\
\text { (Section 4.2) }\end{array}$ & $\begin{array}{l}\text { Mandatory requirements that vary across jurisdictions, } \\
\text { which govern the generation, handling, storage, treatment, } \\
\text { transport, recycling, and disposal of hazardous wastes, which } \\
\text { may include large-format LiBs accumulated or stored before } \\
\text { recycling or disposal, and those being recycled or disposed of. } \\
\text { Hazardous waste requirements are also more stringent than the } \\
\text { non-hazardous solid waste requirements. }\end{array}$ & $\begin{array}{l}\text { Recycle, } \\
\text { disposal }\end{array}$ \\
\hline $\begin{array}{l}\text { Universal } \\
\text { hazardous waste } \\
\text { law and regulations } \\
\text { (Section 4.3) }\end{array}$ & $\begin{array}{l}\text { Optional alternative hazardous waste requirements that vary } \\
\text { across jurisdictions, which govern the generation, handling, } \\
\text { storage, transport, recycling, and disposal of specified types of } \\
\text { waste, which may include large-format LiBs accumulated or } \\
\text { stored before recycling or disposal, and those being recycled or } \\
\text { disposed of. Universal hazardous waste requirements are a } \\
\text { subset of and are less stringent than hazardous waste } \\
\text { requirements, but more stringent than non-hazardous solid waste } \\
\text { requirements. }\end{array}$ & $\begin{array}{l}\text { Recycle, } \\
\text { disposal }\end{array}$ \\
\hline $\begin{array}{l}\text { Hazardous } \\
\text { materials } \\
\text { transportation } \\
\text { regulations } \\
\text { (Section } 4.5)\end{array}$ & $\begin{array}{l}\text { Mandatory requirements that govern U.S. interstate commerce } \\
\text { shipping and transport of hazardous materials across, which may } \\
\text { include large-format LiBs being shipped or transported across } \\
\text { state lines for reuse, recycling or disposal }\end{array}$ & $\begin{array}{l}\text { Reuse, } \\
\text { recycle, } \\
\text { disposal }\end{array}$ \\
\hline $\begin{array}{l}\text { Hazardous waste } \\
\text { export regulations } \\
\text { (Section } 4.5 .4)\end{array}$ & $\begin{array}{l}\text { Mandatory requirements that govern the export, shipping, } \\
\text { and transport of hazardous materials to other countries, which } \\
\text { may include large-format LiBs being exported, shipped, or } \\
\text { transported for reuse, recycling, or disposal }\end{array}$ & $\begin{array}{l}\text { Reuse, } \\
\text { recycle, } \\
\text { disposal }\end{array}$ \\
\hline
\end{tabular}

\subsection{Regulation of LiBs as Solid Waste}

Decommissioned LiBs that are discarded and not directly reused may be subject to U.S. federal, state, and/or local solid waste requirements pursuant to the Resource Conservation and Recovery 
Act of 1976 (RCRA). ${ }^{36,37}$ In relevant part, RCRA defines solid waste to include "other discarded material." 38 RCRA regulations define "discarded material" to include materials "disposed of," "burned or incinerated," "recycled," or "accumulated, stored, or treated before or in lieu of being recycled or disposed of." "39 By this definition, LiBs accumulated or stored before recycling and those being recycled or disposed of may be regulated as solid waste pursuant to RCRA.

Subtitle D of RCRA grants authority to states to regulate non-hazardous solid waste pursuant to federal guidelines that set minimum standards for the operation of state and local management of solid waste. ${ }^{40}$ However, states have the authority to set more stringent requirements than the federal standards and to define what constitutes solid waste in their own regulations. ${ }^{41}$ States may also delegate regulatory authority to local governments (EPA 2019d). Accordingly, the types of materials that qualify as "solid waste" may vary across jurisdictions.

The person that determines that the $\mathrm{LiB}$ is "discarded material" has the responsibility and potential legal liability to determine if the LiB is a "solid waste" in their state or local jurisdiction. Anecdotal evidence suggests there is confusion about whether certain reuse and recovery processes for LiBs would trigger RCRA regulation. ${ }^{42,}{ }^{43}$ Reuse of a LiB, without modification, for secondary use applications would not be regulated pursuant to RCRA. ${ }^{44,45}$ There is also an argument that LiBs that undergo minor processing for reuse in secondary use applications would not be regulated under RCRA. ${ }^{46,47}$ However, the reuse of LiBs for secondary use applications may require reconditioning or refurbishment, which may include processes that constitute a material being "recycled" or "reclaimed." RCRA regulations define "recycled" to include "reclamation," which may trigger RCRA compliance. RCRA regulations define "reclamation," in part to include "...material processed to recover a usable product or if it is regenerated. Examples are recovery of lead values from spent batteries and regeneration of spent solvents." ${ }^{48}$ If a LiB requires processing before reuse, and the processing meets the regulatory definition of reclamation, it could be considered a spent material ${ }^{49}$ and regulated as solid waste and potentially as hazardous waste pursuant to RCRA (EPA 2014). Similarly, it is unclear whether new recovery processes such as cathode relithiation would constitute "reclamation" and trigger RCRA regulation. ${ }^{50}$ If new resource recovery processes for LiBs meet the definition of reclamation, the material could be regulated as hazardous waste pursuant to RCRA (EPA 2014).

3642 U.S.C. $\S 6903(27)$

${ }^{37} 40$ C.F.R. $\S 261.2(\mathrm{e})(1)$

3842 U.S.C. $\$ 6903(27)$

3940 C.F.R. $\S \S 261.2(\mathrm{a})$-(c); 42 U.S.C. $\S 6903(27) ; 40$ C.F.R. $\S 261.2(\mathrm{e})(\mathrm{ii})$

4042 U.S.C. $\$ 6941 ; 40$ C.F.R. $\$ \S 239-259$

4142 U.S.C. $\S 6941 ; 40$ C.F.R. $\S \S 239-259$

${ }^{42}$ David Wagger, ISRI, email, August 3, 2020

${ }^{43}$ Daniel Stoehr, Daniels Training Services, Inc., teleconference, August 30, 2019

4442 U.S.C. $§ 6903(27)$

4540 C.F.R. $§ 261.2(\mathrm{e})(1)(\mathrm{ii})$

4640 C.F.R. $\$ 261.2(\mathrm{e})$

${ }^{47}$ David Wagger, ISRI, email, August 3, 2020

4840 C.F.R. $\S 261.2(\mathrm{c})(3)$

${ }^{49}$ A "spent material" is defined as any material that has been used and as a result can no longer serve the purpose for which it was produced without processing (40 C.F.R. § 261.1(c)(1); EPA 2014).

${ }^{50}$ David Wagger, ISRI, email, August 3, 2020 
When a person determines that a $\mathrm{LiB}$ is discarded (e.g., constitutes a solid waste), they become a regulated entity (e.g., generator $)^{51}$ and may be subject to federal, state, and/or local RCRA solid and hazardous waste regulations unless an exclusion applies. In certain circumstances, discarded LiBs may be excluded from solid waste regulations if they are recycled ${ }^{52}$ (Section 4.1.1). If an exclusion from the solid or hazardous waste regulations does not apply, then the generator must make a hazardous waste determination ${ }^{53}$ (Section 4.1.2). Discarded LiBs that exhibit hazardous characteristics (i.e., reactivity) are subject to mandatory jurisdictional hazardous waste requirements. If the generator determines that discarded $\mathrm{LiB}$ is not hazardous, the generator must comply with applicable non-hazardous solid waste regulations.

\subsubsection{Materials Excluded from the Definition of Hazardous Solid Waste}

Certain LiBs may be excluded from the definition of solid waste, and RCRA federal hazardous waste regulation if they are recycled. ${ }^{54}$ Exclusions under RCRA are specific to the type of material being recycled, the recycling processes used, and how the recovered resources are used. Examples of exclusions that could potentially apply to recycling LiBs include:

- Hazardous secondary material ${ }^{55}$ generated and legitimately reclaimed within the United States or its territories and under the control of the generator, ${ }^{56}$ provided certain regulatory requirements are met $^{57}$

- Hazardous secondary material that is generated and then transferred for the purpose of reclamation, provided certain regulatory requirements are met $^{58}$

- Hazardous secondary material that is exported from the United States and reclaimed at a reclamation facility located in a foreign country, provided certain regulatory requirements are met $^{59}$

To meet any of these exclusions from RCRA hazardous waste regulation the person who generates the hazardous secondary material and the recycler must ensure the:

- Hazardous secondary material is managed as a valuable commodity when it is under their control

- Hazardous secondary material provides a useful contribution to the recycling process or to a product or intermediate recycling process

- Recycling process produces a valuable product or intermediate

- Recycled product is comparable to products in the same category. ${ }^{60}$

5140 C.F.R. $\S 273.9$

5240 C.F.R. $\S 261.4$ (a)

${ }^{53} 40$ C.F.R. $\S \S 261.3(\mathrm{a})(2) ; 261.10,261.20-.24 ; 262.11$

${ }^{54} 40$ C.F.R. $\S 261.4(\mathrm{a})$

${ }^{55}$ A "hazardous secondary material" is a material that requires reclamation before reuse, that when discarded (which may include recycling), would be identified as a hazardous waste (40 C.F.R. § 260.10; EPA 2014).

${ }^{56} \mathrm{~A}$ "generator" is any person, by site, whose act or process produces hazardous waste identified or listed in 40

C.F.R. $\S 261$ or whose act first causes a hazardous waste to become subject to regulation (40 C.F.R. $\S 260.10$ ).

${ }^{57} 40$ C.F.R. $\S 261.4(\mathrm{a})(23)$

5840 C.F.R. $\S 261.4(\mathrm{a})(24)$

5940 C.F.R. $\$ 261.4(\mathrm{a})(25)$

6040 C.F.R. $\S 260.43$ 
Consideration: The EPA may authorize states and U.S. territories to administer a hazardous waste program in lieu of the federal program (EPA 2019a, 2019b). ${ }^{61}$ State-administered hazardous waste programs must be at least as stringent as RCRA, but they may include requirements beyond federal requirements (EPA 2019a, EPA 2019b). States with authority to administer a hazardous waste program may choose to adopt or not adopt the federal exclusions above (Section 4.1.1).

There is evidence of conflicting jurisdictional views on which, if any, exclusions from the definition of solid waste may apply to recycling LiBs.

\subsubsection{RCRA Hazardous Waste Determination}

If an exclusion does not apply, LiBs meeting the definition of solid waste are regulated as a hazardous waste if they are (1) a listed ${ }^{62}$ hazardous waste or (2) exhibit one or more hazardous characteristics (i.e., ignitability, corrosivity, reactivity, or toxicity). ${ }^{63}$ The person that generates $\mathrm{LiB}$ solid waste (or determines that the $\mathrm{LiB}$ is solid waste) has the responsibility and legal liability to determine if the $\mathrm{LiB}$ is hazardous. ${ }^{64}$ Current large-format LiB designs contain flammable electrolytes and can exhibit hazardous characteristics of reactivity and they may be subject to hazardous waste regulations in the United States when they are "discarded" unless another provision, ${ }^{65}$ exclusion, ${ }^{66}$ or exemption ${ }^{67}$ applies (Chupka 2020; Cano et al. 2018). ${ }^{68}$

To determine whether the LiB exhibits hazardous characteristics, the person that generates the LiB waste should use "acceptable knowledge." 69 Examples of acceptable knowledge include "process knowledge (e.g., information about chemical feedstocks and other inputs to the production process); knowledge of products, by-products, and intermediates produced by the manufacturing process; chemical or physical characterization of wastes; information on the chemical and physical properties of the chemicals used or produced by the process or otherwise contained in the waste; testing that illustrates the properties of the waste; other reliable and relevant information about the properties of the waste or its constituents." 70

${ }^{61}$ All 50 states and all U.S. territories have the option to administer a hazardous waste program under RCRA (EPA 2019a, 2019b). However, Alaska, Iowa, Puerto Rico, and the U.S. Virgin Islands do not have an EPAapproved hazardous waste program (EPA 2019a, 2019b).

${ }^{62}$ Because LiBs are not listed as hazardous wastes under RCRA regulations, any discussion of listed hazardous wastes is outside the scope of this report.

${ }^{63} 40$ C.F.R. $\S \S 261.3(\mathrm{a})(2) ; 261.10,261.20-.24$

${ }^{64} 40$ C.F.R. $\$ 262.11$

6540 C.F.R. $\S \S 261.2(\mathrm{e})(1)(\mathrm{ii})$

6640 C.F.R. $\S 261.4(\mathrm{a})$

6740 C.F.R. $§ 261.6($ a)(2)(iv) (provision is for lead acid batteries, and is used as an example of exemption that could be created for LiBs)

6840 C.F.R. $\S \S 261.21(\mathrm{a})(2) ; 261.3 ; 273.2(\mathrm{c})(1)$

${ }^{69}$ There are currently no EPA test methods prescribed to measure reactivity; accordingly, a generator should use "acceptable knowledge" to determine whether a solid waste exhibits a hazardous characteristic (EPA 2009).

7040 C.F.R. $\S 261.11(d)(1)$ 


\subsection{Regulation of LiBs as Hazardous Waste}

$\mathrm{LiBs}$, regulated as hazardous waste, that are accumulated, stored, or treated ${ }^{71}$ before recycling or disposal and those being recycled or disposed of must follow stringent handling requirements pursuant to RCRA.

\section{Hazardous Waste Generation}

A person who generates ${ }^{72}$ hazardous waste is regulated based on the amount of hazardous waste they produce per month. Three federal subcategories of hazardous waste generators have been established by federal regulation:

- Very small quantity generators are entities that generate 100 kilograms (kg) (roughly 220 pounds) or less of hazardous waste per month

- Small quantity generators are entities that generate between $100 \mathrm{~kg}$ (roughly 220 pounds) and 1,000 kg (roughly 2,200 pounds) of hazardous waste per month

- Large quantity generators are entities that generate $1,000 \mathrm{~kg}$ (roughly 2,200 pounds) or more of hazardous waste. ${ }^{73}$

The status of a hazardous waste generator for large-format LiBs can vary based on the weight of the LiB and the generation or accumulation amount. The weight of LiBs for use in BES systems varies depending on their voltage and capacity (PowerScout 2017). LiBs for use in EVs weigh approximately 40-60 pounds, while LiBs for stationary BES may weigh more than 200 pounds (PowerScout 2017). A generator's status may also change month-to-month if their monthly accumulation or generation amount changes. ${ }^{74,75}$

Consideration: Based on the Li-BES weights above, any person that has approximately 37 to 56 or more used EV batteries, or 12 or more used stationary batteries may be considered a RCRA large quantity generator subject to stringent regulatory requirements and potential legal liability for noncompliance.

\subsection{Regulation of LiBs as Universal Waste}

EPA regulates batteries, including large-format LiBs, as a category of hazardous waste that may be managed as universal waste (CalEPA 2019; EPA 2019a). ${ }^{76}$ Universal waste is a subset of hazardous waste that generally has less-stringent waste management requirements than hazardous waste regulations. ${ }^{77,78}$ The EPA passed universal waste regulations to streamline

\footnotetext{
${ }^{71}$ Under RCRA hazardous waste regulations, "treatment" means "any method, technique, or process, including neutralization, designed to change the physical, chemical, or biological character or composition of any hazardous waste so as to neutralize such waste, or so as to recover energy or material resources from the waste, or so as to render such waste non-hazardous, or less hazardous; safer to transport, store, or dispose of; or amenable for recovery, amenable for storage, or reduced in volume" (40 C.F.R. § 260.10).

${ }^{72}$ A hazardous waste generator means "any person, by site, whose act or process produces hazardous waste or whose act first causes a hazardous waste to become subject to regulation" (40 C.F.R. §260.10).

7340 C.F.R. $\$ 260.10$

7440 C.F.R. $\$ 262.13$

${ }^{75}$ Daniel Stoehr, Daniels Training Services, Inc., teleconference, August 30, 2019

7640 C.F.R. $\S \S 260-265,273$

${ }^{77}$ Universal Waste Rule, 60 Fed. Reg. 25,492, 25,492 (May 11, 1995) (to be codified at 40 C.F.R. Parts 9, 260, 261, $262,264,265,266,268,270$, and 273).

7840 C.F.R. $\S \S 260-265,273$
} 
hazardous waste management regulations and encourage collection and recycling of certain categories of hazardous waste (EPA 2019a) ${ }^{79,80}$ Generators and others handling these waste streams are not required to manage their qualifying hazardous waste as universal waste; universal waste regulations are an optional alternative to the hazardous waste regulations for qualifying hazardous wastes. ${ }^{81}$

Consideration: The EPA has also created alternative regulatory controls for certain material when they are recycled to encourage the collection and recycling of certain categories of hazardous waste. Lead-acid batteries may be regulated as universal waste or may be regulated pursuant to alternative regulatory controls that have less-stringent requirements for the handling, regeneration, collection, and storage of spent lead-acid batteries before reclamation. ${ }^{82}$ Unlike universal waste regulation this alternative regulatory control only applies to lead-acid batteries destined for resource recovery. A similar designation for LiBs could reduce liability concerns and make the economics of recycling LiBs more competitive with disposal.

Because the universal waste rules are less stringent than the hazardous waste rules, any state that administers its own RCRA hazardous waste program can choose to adopt any or none of the federal universal waste categories (EPA 2019a). States may also delegate regulatory authority to local governments (EPA 2019a). Accordingly, state and local universal waste program requirements for the handling, storage, transport, and treatment of LiBs may vary by jurisdiction (EPA 2019a). As of October 2020, all 50 states and the District of Columbia allow batteries to be managed as universal waste rather than hazardous waste (EPA 2019a) ${ }^{83}$

\section{Universal Waste Handling}

A person who handles universal waste is regulated based on the amount of universal waste accumulated at any time. Two federal subcategories of universal waste handlers have been established by federal regulation:

- Small quantity handlers of universal waste are entities that accumulate less than 5,000 $\mathrm{kg}$ (roughly 11,000 pounds) of universal waste at any time

- Large quantity handlers of universal waste are entities that accumulate 5,000 or more $\mathrm{kg}$ of universal waste at any time. ${ }^{84}$

Similar to the discussion above (Section 4.1.2), the status of universal waste handlers for largeformat $\mathrm{LiBs}$ can vary based on the weight of the $\mathrm{LiB}$ and the generation or accumulation amount. The weight of LiBs for use in BES systems varies depending on their voltage and capacity (PowerScout 2017). LiBs for use in EVs weigh approximately 40-60 pounds, while LiBs for stationary BES may weigh more than 200 pounds (PowerScout 2017). A generator's status may

\footnotetext{
${ }^{79} 40$ C.F.R. $\S \S 260-265,273$

${ }^{80}$ Universal Waste Rule, 60 Fed. Reg. 25,492, 25,492 (May 11, 1995) (to be codified at 40 C.F.R. Parts 9, 260, 261, $262,264,265,266,268,270$, and 273)

8140 C.F.R. $\S 273.1(b)$

8240 C.F.R. $\S 266.80$

${ }^{83}$ Kathy Lett, U.S. EPA, email correspondence, September 30, 2020

8440 C.F.R. $§ 273.9$
} 
also change month-to-month if their monthly accumulation or generation amount reaches a higher or lower threshold. ${ }^{85,86}$

Consideration: Based on the Li-BES weights above, any person that has approximately $183-275$ or more used EV batteries, or 55 or more used stationary batteries may be considered a large quantity handler of universal waste.

\subsection{Comparison of Hazardous Waste and Universal Waste Handling, Storage, and Transport Requirements}

In this section, we compare federal RCRA handling, storage, and transport requirements for materials designated as hazardous waste and universal waste. It is important to note that states that have authorization to administer their own hazardous waste programs may choose to include requirements beyond the federal requirements discussed in this section (EPA 2019d, EPA 2019e).

\subsubsection{Generator and Handler Requirements}

Generally, handling requirements vary based on the classification of waste (i.e., hazardous or universal) and the quantity of waste produced or accumulated. Table 6 compares federal requirements for hazardous waste generators and universal waste handlers.

Table 6. Federal Hazardous Waste Generator and Universal Waste Handler Requirements ${ }^{a}$

\begin{tabular}{|c|c|c|c|c|c|}
\hline \multirow[b]{2}{*}{ Requirement } & \multicolumn{3}{|c|}{ Hazardous Waste } & \multicolumn{2}{|c|}{ Universal Waste } \\
\hline & $\begin{array}{l}\text { Very Small } \\
\text { Quantity } \\
\text { Generators }\end{array}$ & $\begin{array}{l}\text { Small } \\
\text { Quantity } \\
\text { Generators }\end{array}$ & $\begin{array}{l}\text { Large } \\
\text { Quantity } \\
\text { Generators }\end{array}$ & $\begin{array}{l}\text { Small } \\
\text { Quantity } \\
\text { Handlers of } \\
\text { Universal } \\
\text { Waste }\end{array}$ & $\begin{array}{l}\text { Large } \\
\text { Quantity } \\
\text { Handlers of } \\
\text { Universal } \\
\text { Waste }\end{array}$ \\
\hline $\begin{array}{l}\text { EPA } \\
\text { identification } \\
\text { number }\end{array}$ & Not required & Required & Required & Not required & Required \\
\hline $\begin{array}{l}\text { On-site } \\
\text { accumulation } \\
\text { limit (total at } \\
\text { one time) }\end{array}$ & $\begin{array}{l}\text { Less than } \\
1,000 \mathrm{~kg} \\
\text { (roughly } 2,200 \\
\text { pounds) }\end{array}$ & $\begin{array}{l}\text { Less than } \\
6,000 \mathrm{~kg}\end{array}$ & No limit & $\begin{array}{l}\text { Less than } \\
5,000 \mathrm{~kg} \\
\text { (roughly } \\
11,000 \\
\text { pounds) }\end{array}$ & No limit \\
\hline $\begin{array}{l}\text { Storage time } \\
\text { limit (without } \\
\text { a RCRA } \\
\text { permit) }\end{array}$ & No limit & $\begin{array}{l}\text { Less than } 180 \\
\text { days (or less } \\
\text { than } 270 \text { days } \\
\text { if transporting } \\
\text { more than } 200 \\
\text { miles) }\end{array}$ & $\begin{array}{l}\text { Less than } 90 \\
\text { days }\end{array}$ & 1 year ${ }^{b}$ & 1 yearc \\
\hline
\end{tabular}

8540 C.F.R. $\S 262.13$

${ }^{86}$ Daniel Stoehr, Daniels Training Services, Inc., teleconference, August 30, 2019 


\begin{tabular}{|l|l|l|l|l|l|}
\hline \multirow{2}{*}{ Requirement } & \multicolumn{3}{|c|}{ Hazardous Waste } & \multicolumn{2}{c|}{ Universal Waste } \\
\cline { 2 - 6 } & $\begin{array}{l}\text { Very Small } \\
\text { Quantity } \\
\text { Generators }\end{array}$ & $\begin{array}{l}\text { Small } \\
\text { Quantity } \\
\text { Generators }\end{array}$ & $\begin{array}{l}\text { Large } \\
\text { Quantity } \\
\text { Generators }\end{array}$ & $\begin{array}{l}\text { Small } \\
\text { Quantity } \\
\text { Handlers of } \\
\text { Universal } \\
\text { Waste }\end{array}$ & $\begin{array}{l}\text { Large } \\
\text { Quantity } \\
\text { Handlers of } \\
\text { Universal } \\
\text { Waste }\end{array}$ \\
\hline Manifest \\
\end{tabular}

a The table is from EPA (2019a). It reflects only the federal minimum requirements; it does not reflect state or local requirements.

${ }^{b}$ Small quantity handlers of universal waste may accumulate universal waste for longer than one year if they can prove the extended accumulation period is solely for the purpose of accumulating enough of the universal waste to facilitate proper recovery, treatment, or disposal (40 C.F.R. $\S 273.15(b)$ )

${ }^{c}$ Large quantity handlers of universal waste may accumulate universal waste for longer than one year if they can prove the extended accumulation period is solely for the purpose of accumulating enough of the universal waste to facilitate proper recovery, treatment, or disposal (40 C.F.R. $\S 273.35(\mathrm{~b})$ ).

d A manifest is "the shipping document EPA Form 8700-22 (including, if necessary, EPA Form 8700-22A), or the electronic manifest, originated and signed in accordance with the applicable requirements" (40 C.F.R. § 260.10). The manifest includes information about the type and quantity of the waste being transported, instructions for handling the waste, and spaces for signatures of every party involved in the entire process (EPA 2019c). 


\subsubsection{Treatment, Storage, and Disposal Facility and Destination Facility Requirements}

Any person that stores LiBs, classified as hazardous or universal waste, prior to recycling or disposal may be subject to more RCRA requirements. Hazardous waste generators who store LiBs classified as hazardous waste before recycling/disposal, or secondary hazardous material before reclamation longer than the generator regulations (Section 4.4.1) allow must comply with hazardous waste treatment, storage, and disposal facility (TSDF) requirements or be subject to a penalty for noncompliance. ${ }^{87,88}$ Similarly, universal waste handlers that store LiBs classified as universal waste before recycling (which includes reclamation) longer than the handler regulations allow (Section 4.4.1) must comply with a universal waste destination facility requirements or be subject to a penalty for noncompliance (EPA 2019d). ${ }^{89,90,91}$

Third-party recyclers that accept LiBs classified as hazardous or universal waste must also comply with TSDF or destination facility regulatory requirements if they store LiBs for any amount of time before recycling or disposal..$^{92}$ Recyclers that do not store hazardous or universal waste before recycling or disposal are not subject to TSDF or destination facility requirements, but must still comply with notice, manifest, reporting, and other federal requirements outlined in 40 C.F.R. $\S \S 261.6(\mathrm{c})-(\mathrm{d})$.

The main difference between regulation as a hazardous waste TSDF and a universal waste destination facility is that TSDF's have a manifest requirement, and universal waste destination facilities do not, but they must keep waste shipment receipt records on site. ${ }^{93}$ Federal requirements for hazardous waste TSDFs and universal waste destination facilities include:

- Notification about location and description of waste type and management activities

- EPA identification number

- RCRA permit

- Chemical and physical analysis of incoming waste

- Security measures and facility inspections

- Personnel training

- Facility siting location standards compliance

- Communication/alarm system and safety equipment

- Coordination with local authorities on precautionary arrangements

- Contingency plan management

- On-site or on-call emergency coordinator

- Manifests (required for TSDFs only, destination facilities must keep shipment records on site)

- Facility operating records

8740 C.F.R. $\S \S 264.1,260.10,261.6(c)(1)-(c)(2)$

8840 C.F.R. $\$ 260.10$

8940 C.F.R. $\$ 273.60$ (b)

9040 C.F.R. $\S 261.6(\mathrm{c})(2)$

9140 C.F.R. $\S 273.60$

9240 C.F.R. $\S \S 264.6(\mathrm{c})(2)$

${ }^{93} 40$ C.F.R. $§ 273.62$ 
- Biennial reports regarding the nature, quantities, and disposition of waste generated at the facility, which must be submitted to the EPA or state regulators

- Groundwater standard violation detection, monitoring, and response program

- Closure and post-closure plans, cost estimations, and assurances

- Air emission standards for process vents and equipment leaks ${ }^{94}$

\subsection{Transport and Export Requirements}

Transporters of LiBs regulated as hazardous waste or universal waste may be subject to specific packaging, documentation, and other transit-related requirements. Also, export regulation may apply. In this section, we discuss the RCRA hazardous and universal transporter regulations, as well as U.S. Department of Transportation (DOT) hazardous material regulations (HMR) ${ }^{95}$ for highway and rail transport, air transport, and sea transport. In addition, we discuss RCRA hazardous and universal waste and international transboundary export requirements.

RCRA defines hazardous and universal waste transporters as persons engaged in the offsite transportation of hazardous or universal waste by air, rail, highway, or water. ${ }^{96}$ Table 7 compares the federal requirements for hazardous and universal waste transporters.

Table 7. Federal Hazardous Waste Transporter and Universal Waste Transporter Requirements ${ }^{\mathrm{a}}$

\begin{tabular}{|l|l|l|}
\hline Requirement & Hazardous Waste Transporter & Universal Waste Transporter \\
\hline EPA identification number & Yes & No \\
\hline Manifest & Yes & No \\
\hline Release response & Yes & $\begin{array}{l}\text { Yes (but with less-stringent } \\
\text { requirements) }\end{array}$ \\
\hline $\begin{array}{l}\text { Universal waste handler } \\
\text { regulations (Section 4.3.1) }\end{array}$ & No & $\begin{array}{l}\text { Yes, if universal waste is stored at } \\
\text { transfer facilityc for more than 10 } \\
\text { days }\end{array}$ \\
\hline $\begin{array}{l}\text { Hazardous waste TSDF } \\
\text { regulations (Section 4.3.2) }\end{array}$ & $\begin{array}{l}\text { Yes, if hazardous waste is stored } \\
\text { at a transfer facilityd for more than } \\
10 \text { days }\end{array}$ & No \\
\hline
\end{tabular}

a The table reflects only the federal minimum; it does not reflect state or local requirements (40 C.F.R. $\S \S$ 260, 263, 273; EPA 2019d)

${ }^{b}$ Refers to the action(s) a transporter must take in the event of a hazardous or universal waste discharge or release during transportation (40 C.F.R. §§ 263.30-31, 273.54).

c "Universal waste transfer facility means any transportation-related facility including loading docks, parking areas, storage areas and other similar areas where shipments of universal waste are held during the normal course of transportation for ten days or less" (40 C.F.R. $\S 273.9$ ).

${ }^{\mathrm{d}}$ Hazard waste transfer facility means any transportation-related facility, including loading docks, parking areas, storage areas and other similar areas where shipments of hazardous waste or hazardous secondary materials are held during the normal course of transportation (40 C.F.R. § 260.10).

9440 C.F.R. $\S \S 273.60-.62$

9549 C.F.R. $\S \S 171-180$

9640 C.F.R. $\S \S 260.10,273.9$ 


\subsubsection{Highway and Rail Transport}

RCRA hazardous and universal waste transporters of LiBs must also comply with DOT hazardous material regulation. ${ }^{97}$ DOT regulates lithium batteries (herein LiBs) ${ }^{98}$ as a Class 9 hazardous material (Chupka 2020; Bartlett et al. 2017; Gaines, Richa, and Spangenberger 2018)..${ }^{99,100} \mathrm{~A}$ hazardous material is defined in part as "a substance or material that...is capable of posing an unreasonable risk to health, safety, and property when transported in commerce." 101 Any person transporting LiBs by highway or railway that is classified as hazardous material is also subject to DOT's hazardous material regulations. ${ }^{102,103}$ The transportation regulations for LiBs vary by mode of transport (e.g., air or highway). DOT hazardous material regulations may include (dependent on energy capacity of the battery and mode of transportation):

- Packaging specifications ${ }^{104}$

- Hazard communication requirements, such as marking and labeling packages ${ }^{105}$

- Batteries must be a type proven to meet the criteria in part III, sub-section 38.3 of the United Nations Manual of Tests and Criteria ${ }^{106}$

- Hazardous materials shipping papers for of all hazardous materials within a shipment, including their basic description, quantities, types of package, shipper's certification, and Emergency Response Information/Telephone Number ${ }^{107}$

- Hazardous materials training for all hazmat employees ${ }^{108}$

\footnotetext{
9749 C.F.R. $\S 173.21$

${ }^{98}$ For consistency, the authors use the abbreviation "LiBs" in section 4.4.1 of this report. However, DOT regulations use the term "lithium batteries" rather than the abbreviation LiBs (49 C.F.R. § 172.101); Jordan Rivera, U.S. Department of Transportation, Headquarters, email, September 30, 2020; Neal Suchak, U.S. Department of Transportation, Headquarters, email, September 30, 2020.

9949 C.F.R. $§ 173.2$

${ }^{100}$ Daniel Stoehr, Daniels Training Services, Inc., teleconference, August 30, 2019

10149 C.F.R. $\S 171.8$

10249 U.S.C. $\S \S 5101-5128$

${ }^{103}$ The DOT authorizes compliance with the International Civil Aviation Organization's Technical Instructions, the International Air Transport Association's Dangerous Goods Regulation, and the International Maritime Dangerous Goods Code to meet DOT standards for air and sea transport, respectively (49 C.F.R. § 171.22(a); 49 C.F.R. § 171.7(v); PHMSA 2017a; PHMSA 2017b). These standards are discussed below in Sections 4.5 and 4.6.

10449 C.F.R. $\S 173.185$ (Under the regulation, LiBs must always be transported per the packaging specifications in 49 C.F.R. $\S 173.185$ (c) to prevent spark creation or heat generation).

10549 C.F.R. $\S \S 172.300-172.338 ; 172.400-172.450$

10649 C.F.R. $\$ 171.7$

10749 C.F.R. $\S 172.200-172.205$

10849 C.F.R. $§ 172.704$. A hazmat employee includes a person who is 1) employed on a full or part time basis by a hazmat employer; 2) self-employed transporting hazardous materials in commerce; 3) a railroad signalman or maintenance-of-way employee; 4) a loader or handler or hazardous materials; 5) a designer, inspector or marker of a packaging component qualified for use in transporting hazardous materials; 6) a preparer of hazardous materials for transportation; 7) responsible for transporting hazardous materials; or 8) operates a vehicle used to transport hazardous materials (49 C.F.R. § 171.8).
} 
- Compliance with the United Nations Manual of Tests and Criteria and record keeping requirements ${ }^{109,110}$

Consideration: Persons transporting large-format LiBs (LiBs with a Watt-hour $(\mathrm{Wh})$ rating higher than $100 \mathrm{Wh}$ ) by highway- rather than aircraft or vessel - may qualify for some exceptions to DOT hazardous material requirements related to packaging, labeling, and hazmat employee training, which typically only apply to the transportation of smaller LiBs (LiBs with a rating of $100 \mathrm{Wh}$ or lower). For example, the DOT hazardous materials regulations state that for transportation by highway or rail only, the lithium content of a battery may be increased from $100 \mathrm{Wh}$ to $300 \mathrm{Wh}$ provided that the outer package containing the LiBs is marked: "LITHIUM BATTERIES - FORBIDDEN FOR TRANSPORT ABOARD AIRCRAFT AND VESSEL." 111

\subsubsection{Air Transport}

Any person transporting LiBs for recycling, reuse, or disposal by air should be aware of the International Civil Aviation Organization (ICAO) Technical Instructions. LiBs transported by air are regulated as dangerous goods (e.g., hazardous material) under DOT regulations and ICAO Technical Instructions (FAA 2018). ${ }^{112,113,114,115}$ DOT authorizes the use of the ICAO Technical Instructions for domestic and international aircraft transport. ${ }^{116}$ DOT regulations and ICAO Technical Instructions regulations prescribe stringent packing and labeling requirements for $\mathrm{LiB}$ cargo and require that LiBs be charged to $30 \%$ or less of their capacity. ${ }^{117}$ In addition, DOT regulations and ICAO Technical Instructions (1) prohibit air transport of LiBs that are damaged, defective, or destined for disposal and (2) forbid the shipment of LiBs as cargo on passenger aircraft (Huo et al. 2017). ${ }^{118,119}$

\subsubsection{Vessel Transport}

Any person transporting $\mathrm{LiBs}$ for recycling, reuse, or disposal by vessel should be aware of the International Maritime Dangerous Goods (IMDG) code. DOT authorizes the use of the IMDG code for dangerous goods for domestic and international transport by vessel. ${ }^{120} \mathrm{LiBs}$ are regulated as dangerous goods (e.g., hazardous materials) under DOT and IMDG regulations. ${ }^{121,122}$ The DOT regulations and IMDG code (1) prescribe stringent packaging and

${ }^{109}$ FAA Reauthorization Act of 2018), 84 Fed. Reg. 8006 (Mar. 6, 2019) (to be codified at 49 C.F.R. pt. 172-73; 49 C.F.R. $\S 173.185(d)$. DOT regulations require compliance with the UN Manual of Tests and Criteria, which prescribes procedures for the classification and testing of LiB cells and requires that the results of testing (test reports) be maintained and made available to government officials upon request (49 C.F.R. $\S 173.185(a)$ ).

11040 C.F.R. $\S 273.52$

11149 C.F.R. $\S 173.185$

112 To be codified at 49 C.F.R. pts 172 and 173

${ }^{113}$ Daniel Stoehr, Daniels Training Services, Inc., teleconference, August 30, 2019

11449 C.F.R. $\S 173.2$

${ }^{115}$ Hazardous Materials: Enhanced Safety Provisions for Lithium Batteries Transported by Aircraft, 84 Fed. Reg. 8006 (Mar. 6, 2019)

11649 C.F.R. $\S 171.22$ (a)

${ }^{117}$ Hazardous Materials: Enhanced Safety Provisions for Lithium Batteries Transported by Aircraft, 84 Fed. Reg. 8006 (Mar. 6, 2019) (to be codified at 49 C.F.R. pts 172 and 173)

11849 C.F.R. § 173.185(f)

119 Daniel Stoehr, Daniels Training Services, Inc., teleconference, August 30, 2019

12049 C.F.R. $\S \S 171.7(\mathrm{v}) ; 171.22(\mathrm{a})$

12149 C.F.R. $\S 173.2$

${ }^{122}$ Daniel Stoehr, Daniels Training Services, Inc., teleconference, August 30, 2019 
labeling requirements for $\mathrm{LiB}$ cargo shipped by vessel and (2) require that $\mathrm{LiB}$ cells and batteries be labeled as a Class 9 Miscellaneous Dangerous Goods (Huo et al. 2017). ${ }^{123}$ In addition, the DOT regulations and IMDG code require that LiBs that are damaged, defective, or destined for disposal and shipped by sea display labels indicating the package contains damage or defective LiBs and have additional packaging requirements (e.g., damaged or defective batteries must be transported in individual enclosed inner packaging and be protected against short circuit) (Huo et al. 2017). ${ }^{124}$

\subsubsection{Export}

Any person exporting LiBs from the United States for "resource recovery, recycling, reclamation, direct reuse, or alternatives uses" triggers compliance with RCRA and international transboundary requirements, such as:

- Organization for Economic Cooperation and Development (OECD) Council Decision on the Control of Transboundary Movements of Wastes Destined for Recovery Operations (Council Decision)

- The Basel Convention on the Transboundary Movements of Hazardous Wastes and their Disposal (Basel Convention) (EPA 2019f, 2019d). ${ }^{125,126}$

These international and transboundary requirements may be incorporated within existing domestic regulations (e.g., RCRA) or work in concert with United States regulations, which govern the transportation of LiBs for recycling, reuse, or disposal. For example, RCRA regulations incorporate by reference the OECD requirements and provide specific provisions for exports to Canada. ${ }^{127}$ In addition, although the United States is not a party to the Basel Convention, the OECD requirements largely reflect the Basel Convention requirements. ${ }^{128}$ Further, hazardous wastes such as LiBs are considered "amber list" wastes pursuant to OECD requirements, and they require compliance with international transport agreements and all applicable international and national laws and regulations. ${ }^{129}$ Transboundary export requirements include:

- EPA acknowledgement of consent documenting the specific terms of the destination country's import requirements and consent

- Compliance with the acknowledgement of consent contract requirements, including notification and tracking specifications, movement documentation, and manifest instructions

- Detailed annual reporting to EPA

- Detailed recordkeeping. ${ }^{130}$

\footnotetext{
12349 C.F.R. $\S 173.185$

12449 C.F.R. $\S 173.185(f)$.

12540 C.F.R. $\S \S 262.80,262.81$

${ }^{126}$ Daniel Stoehr, Daniels Training Services, Inc., teleconference, August 30, 2019

12740 C.F.R. $\S \S 262.80-262.83 ; 40$ C.F.R. $\S 260.11$

12840 C.F.R. $\$ 262.83$.

12940 C.F.R. $\$ 262.82($ b)

13040 C.F.R. $\$ 262.83$
} 


\subsection{Penalties for Noncompliance}

Battery energy stakeholders may want to consider civil and criminal liabilities associated with violations of hazardous waste and hazardous materials regulations. Violations may occur during the generation, exportation, handling, transport, treatment, storage, or disposal of LiBs classified as hazardous waste or universal waste, or during the transport of LiBs classified as hazardous materials. This section discusses some, but not all, of the liabilities associated with RCRA and DOT domestic law violations.

\subsubsection{RCRA Hazardous and Universal Waste Regulations}

Noncompliance with any RCRA provision could result in civil and criminal penalties. ${ }^{131}$ The EPA has authority to:

- Issue an order assessing a civil penalty of up to $\$ 101,439$ per violation per day of noncompliance

- Issue an order requiring immediate compliance within a specified period

- Issue both a civil penalty and a compliance order

- Commence a civil action in the appropriate U.S. District Court for penalties and for appropriate injunctive relief, including temporary or permanent injunctions. ${ }^{132}$

The EPA can also assess a penalty of up to $\$ 61,098$ per day of noncompliance after the specified period of a compliance order, and it can suspend or revoke the violator's permits. ${ }^{133}$

Criminal noncompliance with a RCRA provision could also result in a fine of up to $\$ 50,000$, per violation per day, up to two years of imprisonment, or both for:

- Knowingly omitting material information or making any false material statement or representation in any application, label, manifest, record, report, permit, or other document filed, maintained, or used for purposes of compliance with federal or state regulations

- Knowingly generating, storing, treating, transporting, disposing of, exporting, or otherwise handling any characteristic hazardous waste and knowingly destroying, altering, concealing, or failing to file any record, application, manifest, report, or other document required to be maintained or filed for purposes of compliance with regulations

- Knowingly transporting without a manifest, or causing to be transported without a manifest, any "characteristic hazardous waste" required by federal or state hazardous waste regulations to be accompanied by a manifest. ${ }^{134}$

If anyone knowingly commits one of the above violations and also knows that the violation puts another person in imminent danger of death or serious bodily injury, they may be subject to a

13142 U.S.C. $\S 6928$

13240 C.F.R. $\S 19.4$

13340 C.F.R. $\S 19.4$

13442 U.S.C. $\$ 6928(d)$ 
fine of up to $\$ 250,000$ (up to $\$ 1$ million if the violator is an organization), up to 15 years of imprisonment, or both. ${ }^{135}$

Considerations: State penalties for violating hazardous waste regulations may be more stringent than the penalties outlined in federal regulations (EPA 2019a, 2019b). For example, if a person in California intentionally or negligently violates a provision of California hazardous waste laws or regulations or of a permit issued pursuant to those laws and regulations, they could be liable for up to $\$ 70,000$ per violation of a separate provision for each day that the violation continues. ${ }^{136}$

\subsubsection{DOT Hazardous Materials Regulations}

Noncompliance with DOT hazardous materials regulations, orders, special permits, or approvals may result in civil or criminal penalties. ${ }^{137}$ The Secretary of Transportation may bring civil actions to enforce DOT hazardous material regulations, orders, special permits, or approvals, or, if the Secretary has reason to believe an imminent hazard exists, to suspend or restrict transportation of the hazardous material or to eliminate or mitigate the hazard. ${ }^{138}$ Civil penalties could include:

- Up to $\$ 81,993$ for each violation knowingly committed

- Up to $\$ 191,316$ for each violation knowingly committed that results in death, serious illness, or sever injury to any person or in substantial destruction of property

- At least $\$ 493$ per violation related to training. ${ }^{139}$

A separate violation occurs each day the violation continues. ${ }^{140}$

A person who knowingly, willfully, or recklessly violates any DOT hazardous material regulations, orders, special permits, or approvals could be subject to criminal penalties including fines, up to five years of imprisonment (up to 10 years if the violation involves the release of a hazardous material that results in death or bodily injury to a person), or both. ${ }^{141}$

\footnotetext{
13542 U.S.C. $\$ 6928(\mathrm{e})$

${ }^{136}$ Cal. Health and Safety Code $\S 25189$

13749 U.S.C. $\S \S 5122-5124$

13849 U.S.C. § 5122(a)-(b); 49 C.F.R. § 107.301

13940 C.F.R. $\S 107.329$

14049 U.S.C. $\S 5123($ a); 49 C.F.R. § 107.333

14149 U.S.C. $§ 5124(\mathrm{a})$
} 


\section{State Policies}

BES industry stakeholders may want to consider state policies ${ }^{142}$ that explicitly address the reuse, recovery, and disposal of large-format LiBs used in stationary and mobile BES applications. As of January 2021, no U.S. federal policies address reuse or EoL management options for largeformat LiBs. North Carolina and California are the only U.S. states the authors found with policies that directly address reuse and EoL management options for LiBs used in mobile and stationary BES systems. However, Hawaii has proposed a bill that, if enacted, would require a comprehensive study to determine best practices for disposing of and recycling clean energy materials, including batteries. California also has a state-led initiative in policy to study EoL management options for batteries used in mobile and stationary BES applications. Figure 2 maps policies in the United States that address the reuse, recovery, and disposal of large-format LiBs used in stationary and mobile BES applications.

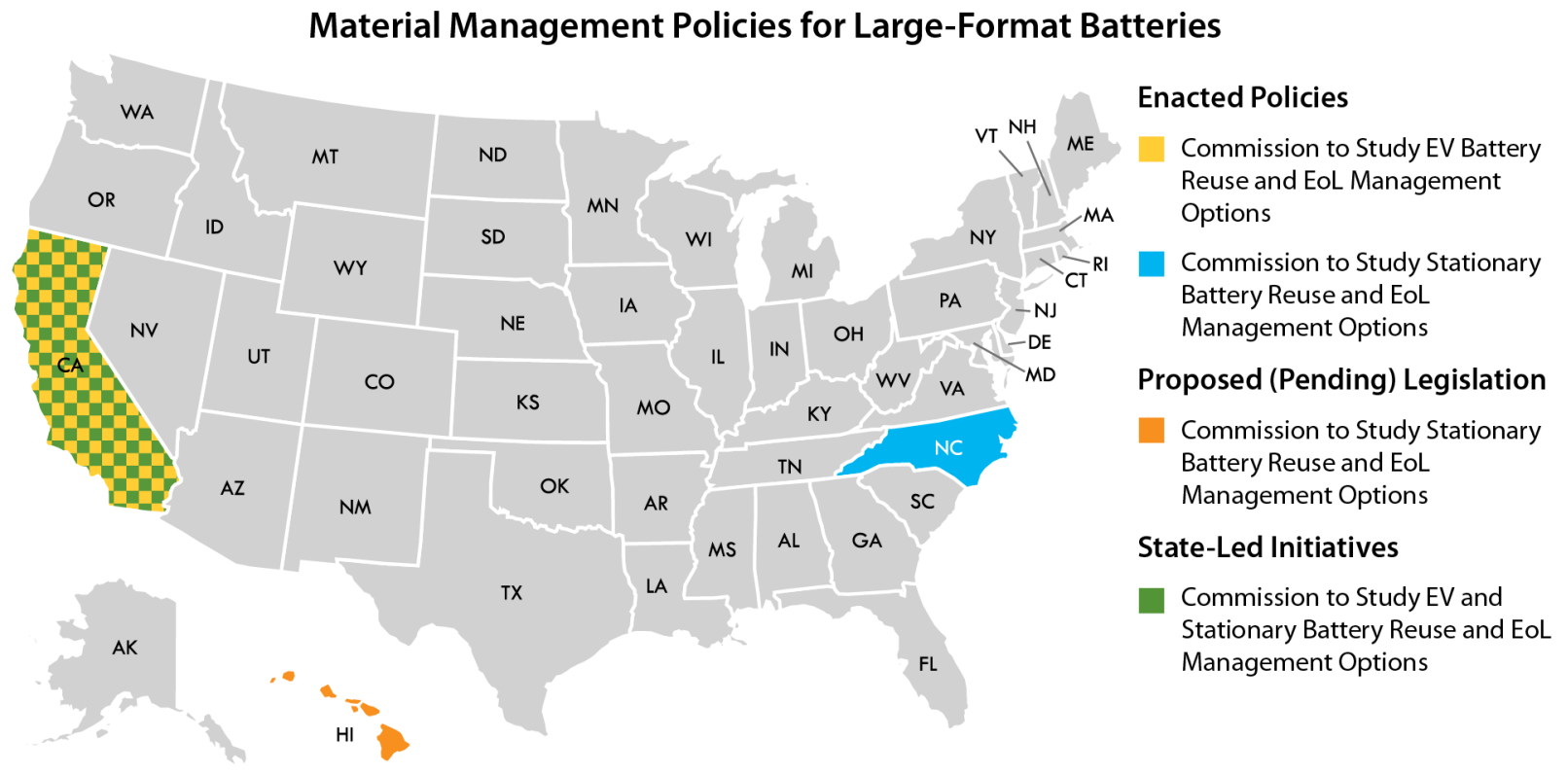

Figure 2. State large-format battery material management policies (enacted, pending, and state-led initiatives)

\subsection{Enacted Policies}

This section summarizes existing U.S. regulations as of January 2021 that explicitly address the reuse/recovery, or disposal of mobile and stationary large-format batteries.

\subsubsection{California}

In 2018, California passed a law to study and recommend policy for the reuse and recycling of EV LiBs. The law tasked the California Environmental Protection Agency (CalEPA) with convening an advisory group to study and provide policy recommendations for the

\footnotetext{
${ }^{142}$ We use "policy" in this report broadly to include not only state statutory and regulatory requirements but also government initiatives and goals and independently formed working groups.
} 
reuse/recovery of "LiBs sold with motor vehicles" (herein EVs). ${ }^{143}$ The law states that the policy recommendations must, at minimum, include:

- Lifecycle considerations for EV LiBs

- Opportunities and barriers to reuse EV LiBs in stationary BES systems

- Best management considerations for EoL EV LiBs

- Overall effect of different management practices on the environment

- Consideration of both in-state and out-of-state options for recycling EV LiBs. ${ }^{144}$

In November 2019, CalEPA convened the Lithium-Ion Car Battery Recycling Advisory Group $^{145}$ to jointly study and address management of EV LiBs (CPUC 2019). The group is required to meet quarterly between April 1, 2019, and April 1, 2022, and consult with universities and research institutions that have conducted research in the area of battery recycling, with manufacturers of electric and hybrid vehicles, and with the recycling industry. ${ }^{146}$ By April 1, 2022, the group must submit policy recommendations to the California state legislature that would ensure that as close to $100 \%$ as possible of EV LiBs in California are reused or recycled at EoL in a safe cost-effective way. ${ }^{147}$

\subsubsection{North Carolina}

In 2019, North Carolina passed a bill to study issues and develop rules for the reuse, recycling, and disposal of stationary "energy storage system batteries." The law tasks the Environmental Management Commission (Commission) and the Department of Environmental Quality (NC DEQ), with considering:

- Whether energy storage system batteries, or constitutes thereof, are properly characterized as solid waste under state and federal law

- Whether energy storage system batteries exhibit characteristics of hazardous solid waste

- The preferred energy storage system batteries material management methods and economic and environmental costs and benefits associated with each method, which includes reuse, refurbishment, recycling, and disposal

- The expected economically productive lifecycle of different types of energy storage system batteries

- The volume of energy storage system batteries deployed in the state, the projected deployment in the future, and the impact that volume would have on state landfills if landfill disposal were permitted

\footnotetext{
${ }^{143}$ Cal. Pub. Res. Code $\S 42450.5(b)$

${ }^{144}$ Cal. Pub. Res. Code $\S 42450.5$ (c)

145 The group must include at least one member from each of the following: California Department of Resources Recycling and Recovery, California Department of Toxic Substances Control, a vehicle manufacturer, an organization that represents one or more vehicle manufacturers, an electronic waste recycler or an organization that represents one or more electronic waste recyclers, an automotive repair dealer or an organization that represents one or more automotive repair dealers, an automobile dismantler or an organization that represents one or more automobile dismantlers, an environmental organization that specializes in waste reduction and recycling, a representative of the energy storage industry, a lithium-ion vehicle battery manufacturer, and a standards-developing organization that has a focus on automotive engineering (Cal. Pub. Res. Code $\S 42450.5$ ).

${ }^{146}$ Cal. Pub. Res. Code $\S 42450.5$

${ }^{147}$ Cal. Pub. Res. Code $\S 42450.5$
} 
- A survey of federal, state, and international regulatory requirements related to energy storage system batteries material management, decommissioning, and financial assurances

- The infrastructure needed to collect and transport energy storage system batteries for reuse, refurbishment, recycling, or disposal

- Whether stewardship programs for recycling EoL energy storage system batteries should be established for applications other than utility-scale solar projects and, if so, fees that should be established for manufacturers to sell energy storage system batteries into the state. ${ }^{148}$

The NC DEQ established a stakeholder process, required by the Act, to inform a regulatory program for the management energy storage system batteries material. ${ }^{149}$ The NC DEQ and the Commission submitted quarterly joint interim reports on their activities and progress to the General Assembly beginning December 1, 2019; the final report was submitted on January 1, 2021. ${ }^{150}$ The final report concluded that some energy storage system batteries, such as LiBs, exhibit hazardous characteristics and that existing regulations for managing hazardous batteries applied to energy storage system batteries (NC DEQ 2021). Accordingly, in the final report NC DEQ and the Commission did not recommend the development of a specific regulatory program for energy storage batteries (NC DEQ 2021).

\subsection{Proposed (Pending) Legislation}

This section summarizes proposed U.S. legislation that addresses reuse/recovery and disposal of mobile and stationary large-format batteries. As of January 2021, the authors found no proposed U.S. federal legislation that expressly speaks to reuse/recovery or disposal of mobile and stationary large-format batteries. However, a bill that was introduced in the legislature of Hawaii addresses reuse and EoL management options for clean energy materials, including batteries. In addition, Arizona proposed a bill in the 2020 legislative session (that failed) that would have created a recycling fund, required a fee by anyone who sells or leased EV batteries in the state, required that EV batteries be sent to state approved recycling facility, and would have prohibited disposal in solid waste landfills. ${ }^{151}$ Although the Arizona bill failed it provides another example of a regulatory framework that could be used to enable reuse and recycling of large-format LiBs.

\subsubsection{Hawaii}

In January 2021, Hawaii proposed House Bill 1333, that, if enacted, would require the Hawaii State Energy Office to work with the Hawaii State Department of Health on a comprehensive study to determine best practices for disposing of and recycling discarded clean energy

\footnotetext{
1482019 N.C. Sess. Law 2019-132

1492019 N.C. Sess. Law 2019-132

1502019 N.C. Sess. Law 2019-132

${ }^{151}$ Arizona proposed House Bill 282 (failed) would have, if enacted, required a fee to sell or lease an EV battery in the state of $\$ 0.85$ per $0.85 \mathrm{~kg}$ of battery weight to the Arizona Department of Revenue; provided an incentivize for manufacturers that established a recycling program to takeback and recycle EV batteries sold or leased into the state; established a recycling fund for orphaned waste; required EV batteries to be sent to a state approved recycling facility; prohibited anyone from disposing EV batteries in a solid waste facility; imposed a civil penalty of $\$ 5,000$ for violation of the law (H.B. 2828, 54th Leg., 2d Reg. Sess. (Ariz. 2020)(failed)).
} 
materials, including batteries. ${ }^{152}$ The bill does not define batteries, but it likely includes stationary large-format batteries because the bill also requires the study to include parts of a solar system (i.e., PV panels, glass, frames, wiring, and inverters) expected to be discarded. ${ }^{153}$ Like North Carolina's law, the bill would require a study to address specific questions, including:

- "The amount of aging PV and solar water heater panels in the State that will need to be disposed of or recycled

- Other types of clean energy materials expected to be discarded in Hawaii in significant quantities, including glass, frames, wiring, inverters, and batteries

- The type and chemical composition of those clean energy materials

- Best practices for collection, disposal, and recycling of those clean energy materials

- Whether a fee should be charged for disposal or recycling of those clean energy materials

- Any other issues that the Hawaii State Energy Office and the Department of Health consider appropriate for management, recycling, and disposal of those clean energy materials" 154

The Hawaii State Energy Office would be required to submit an interim report on the study's progress to the legislature in 2022 and a final report in $2023 .{ }^{155}$ The final report must include findings, recommendations, and any proposed legislation resulting from the study. ${ }^{156}$ A subsection of the bill would appropriate money from the general state revenues to support the purposes of the bill, but the exact amount is yet to be determined. ${ }^{157}$ The bill, if enacted, would go into effect on July 1, 2021. ${ }^{158}$

\subsection{State-Led Initiatives}

In addition to California's legislative mandate to study and recommend policy for the reuse and recycling of mobile and stationary large-format batteries, in 2019, the California Public Utilities Commission (CPUC) and the California Department of Resources Recycling and Recovery (CalRecycle) signed a Memorandum of Understanding (MOU) to cooperate on the development of uniform approaches to waste from EV batteries, energy storage batteries, and related equipment (CPUC and CalRecycle 2019). As of January 2021, the California Energy Commission and the California Air Resources Board also signed onto the 2018 CPUC and CalRecycle memorandum (Teresa Bui, CalRecycle, email, January 8, 2021; Paulina Kolic, CalRecycle, email, September 6, 2019).

${ }^{152}$ H.B. 1333, H.D. 1, 31 st Leg., Reg. Sess. (Haw. 2021)

${ }^{153}$ H.B. 1333, H.D. 1, 31st Leg., Reg. Sess. (Haw. 2021)

${ }^{154}$ H.B. 1333, H.D. 1, 31st Leg., Reg. Sess. (Haw. 2021) (emphasis added)

${ }^{155}$ H.B. 1333, H.D. 1, 31 st Leg., Reg. Sess. (Haw. 2021)

${ }^{156}$ H.B. 1333, H.D. 1, 31st Leg., Reg. Sess. (Haw. 2021)

${ }^{157}$ H.B. 1333, H.D. 1, 31 st Leg., Reg. Sess. (Haw. 2021)

${ }^{158}$ H.B. 1333, H.D. 1, 31 st Leg., Reg. Sess. (Haw. 2021) 


\section{Conclusion}

The expected volume of decommissioned LiBs from EVs and stationary BES systems in the United States presents material management concerns; however, it could also lead to domestic resource recovery and secondary market opportunities. Recovered LiB materials could lead to domestic manufacturing opportunities, reduce resource constraints, and increase supply chain security of critical $\mathrm{LiB}$ resources. $\mathrm{LiB}$ reuse/recycling efforts can also reduce negative environmental impacts associated with the lifecycle of a battery, and lead to new and expanded markets and job creation in the United States.

However, today, there are many technical, economic, and regulatory factors that inhibit a circular economy for LiBs in the United States. In short, these factors impact the accessibility and cost effectiveness of reuse and recycling of large-format LiBs in the U.S and today LiBs are most often disposed of.

Policy measures are needed to enable actors along the BES value chain to proactively and collaboratively act to implement environmentally sustainable management decisions for LiBs. Government-funded R\&D and analysis could lead to the design of durable, more easily reused, and recycled batteries, and to more efficient and cost-effective reuse/recycling services, business models and services. R\&D and analysis could also enable private investment in the early stages of new and expanded BES market opportunities by providing answers to questions that could help alleviate market and regulatory uncertainty. Clearly defined federal and state regulations could mandate and incentivize LiB reuse and recycling-based resource recovery. In addition, changes to the current regulatory scheme for managing solid and hazardous waste could reduce the barriers associated with the handling, transport, accumulation, storage, and processing of LiBs destined for recycling and resource recovery.

Although the scope of this report is limited to mobile and stationary large-format LiB reuse/recycling drivers, barriers, and enablers, as well as regulatory and policy considerations in the United States, future research could analyze and address international efforts to reuse/recycle LiBs. Future research concerning international efforts aimed at $\mathrm{LiB}$ reuse/recycling could further inform efforts in the United States to alleviate market and regulatory uncertainty and expand market opportunities by analyzing the impact of policy and regulatory controls already implemented or in development in other countries. In addition, future research analyzing reuse/recycling regulatory and policy initiatives for small format batteries or other technologies, which have already been implemented, may help further inform our understanding of the drivers, barriers, and enablers to a circular economy for large-format LiBs by providing examples of transferable policies and regulations aimed at incentivizing reuse and recycling and sustainable material management practices. 


\section{References}

Aceleron Energy. n.d. “About." Accessed June 4, 2020. https://www.aceleronenergy.com/.

Ai, Ning, and Katheryn Borucki. 2018. "End-of-Life Electric Vehicle Batteries: U.S. Projections and Management Strategies." Magazine for Environmental Managers (April 2018).

http://pubs.awma.org/flip/EM-Apr-2018/ai.pdf.

Ardani, K., C. Davidson, R. Margolis, and E. Nobler. 2015. A State-Level Comparison of Processes and Timelines for Distributed Photovoltaic Interconnection in the United States. Golden, CO: National Renewable Energy Laboratory. NREL/TP-7A40-63556. January 2015. https://doi.org/10.2172/1227804.

Bade, Gavin. 2019. "U.S. Energy Storage Market Expected to More than Double in 2019, Report Says." Utility Dive (March 6, 2019). https://www.utilitydive.com/news/us-energy-storagemarket-expected-to-more-than-double-in-2019-report-says/549890/.

Bartlett, Dennis, Ted Herman, and Andrew Klinkman. 2017. "Business Models for Extracting More Useful Life from Lithium Ion Battery Systems.” Master's project proposal. Duke University. April 28, 2017.

https://dukespace.lib.duke.edu/dspace/bitstream/handle/10161/14080/Final\%20Masters\%20Proje ct $\% 20-\% 20$ Bartlett_Herman_Klinkman\%20-\%20Second\%20Life $\% 20 \mathrm{Li}-$ ion.pdf? sequence $=1 \&$ isAllowed $=\mathrm{y}$.

BNEF (BloombergNEF). 2020. Electric Vehicle Outlook 2020. May 19, 2020.

Bowler, Melissa. 2014. "Battery Second Use: A Framework for Evaluating the Combination of Two Value Chains." Doctoral thesis, Clemson University. May 2014.

https://tigerprints.clemson.edu/cgi/viewcontent.cgi?referer $=\&$ httpsredir $=1 \&$ article $=2379 \&$ contex $\underline{\mathrm{t}=\text { all } \text { dissertations. }}$

CalEPA (California Environmental Protection Agency). 2019. "Lithium-Ion Car Battery Recycling Advisory Group: Background Information Provided in Preparation for Meeting \#1." November 18, 2019. https://calepa.ca.gov/climate/lithium-ion-car-battery-recycling-advisorygroup/lithium-ion-car-battery-recycling-advisory-group-meeting-materials-11-4-19-background/.

Cano, Zachary P., Dustin Banham, Siyu Ye, Andreas Hintennach, Jun Lu, Michael Fowler, and Zhongwei Chen. 2018. "Batteries and Fuel Cells for Emerging Electric Vehicles Markets." Nature Energy 3: 279-289. https://doi.org/10.1038/s41560-018-0108-1.

CPUC (California Public Utilities Commission). 2019. "Rule 21 Interconnection.” Accessed September 19, 2019. https://www.cpuc.ca.gov/Rule21/.

CPUC and CalRecycle (California Department of Resources Recycling and Recovery). Memorandum of Understanding Between the California Public Utilities Commission and the California Department of Resources Recycling and Recovery. January 8, 2019. https://www. cpuc.ca.gov/uploadedFiles/CPUC_Public_Website/Content/Utilities_and_Industries/Energy_Electricity_and_Natural_Gas/CPUC\%20\%20CalRecycle_MOU_Fully\%20Exctd_1-8-19.pdf. 
Calma, Justine. 2019. "The Electric Vehicle Industry Needs to Figure Out Its Battery Problem." The Verge (November 16, 2019). https://www.theverge.com/2019/11/6/20951807/electricvehicles-battery-recycling.

Casals, Lluc C., Amante Garcia, and Camilla Canal. 2019. "Second Life Batteries Lifespan: Rest of Useful Life and Environmental Analysis." Journal of Environmental Management 232 (February 2019): 354-363. https://doi.org/10.1016/j.jenvman.2018.11.046.

CESA (Clean Energy States Alliance). 2017. Standards and Requirements for Solar Equipment, Installation, and Licensing and Certification: A Guide for States and Municipalities. February 2017. https://www.cesa.org/assets/2017-Files/Standards-and-Requirements-for-Solar.pdf.

Chupka, Marc. 2020. End-of-Life Management of Lithium-Ion Energy Storage Systems. Energy Storage Association. April 22, 2020. https://energystorage.org/wp/wpcontent/uploads/2020/04/ESA-End-of-Life-White-Paper-CRI.pdf.

Cole, P. C., and D. R. Conover. 2016. Energy Storage System Guide for Compliance with Safety Codes and Standards. Richland, WA: Pacific Northwest National Laboratory, and Albuquerque, NM: Sandia National Laboratories. PNNL-SA-118870, and SAND2016-5977R. June 2016. https://doi.org/10.2172/1561496.

Coffin, David and Jeff Horowitz. 2018. "The Supply Chain for Electric Vehicle Batteries." United States Trade Commission Journal of International Commerce and Economics. December 2018.https://www.usitc.gov/publications/332/journals/the supply chain for_electric_vehicle ba tteries.pdf.

Collins, Bryony. 2019. “Electric Car Batteries My Enjoy Life After Death.” BloombergNEF. January 8, 2019. https://www.bnef.com/core/insights/19919.

CPUC and CalRecycle (California Department of Resources Recycling and Recovery). Memorandum of Understanding Between the California Public Utilities Commission and the California Department of Resources Recycling and Recovery. January 8, 2019. https://www. cpuc.ca.gov/uploadedFiles/CPUC_Public_Website/Content/Utilities_and Industries/Energy Electricity and_Natural_Gas/CPUC\%20\%20CalRecycle_MOU_Fully\%20Exctd 1-8-19.pdf.

DOE (U.S. Department of Energy). 2019a. "Department of Energy American Made Lithium-Ion Battery Recycling Prize.” Accessed September 11, 2019. https://americanmadechallenges.org/batteryrecycling/.

- 2019b. Lithium-Ion Battery Recycling Prize: Phase II Official Rules. Last modified August 1, 2019. https://americanmadechallenges.org/batteryrecycling/battery-recycling-prizerules-and-scoring-criteria.pdf.

- N.d. "Batteries for Hybrid and Plug-In Electric Vehicles." U.S. Department of Energy, Energy Efficiency \& Renewable Energy Alternative Fuels Data Center. Accessed October 15, 2020. https://afdc.energy.gov/vehicles/electric batteries.html. 
DTSC (California Department of Toxic Substances Control). 2019. Defining Hazardous Waste. https://dtsc.ca.gov/wp-content/uploads/sites/31/2018/05/DefiningHazardousWaste.pdf.

DOI (United States Department of the Interior). 2018. "Interior Seeks Public Comment on Draft List of 35 Minerals Deemed Critical to U.S. National Security and the Economy." Press Release. February 16, 2018. https://www.doi.gov/pressreleases/interior-seeks-public-comment-draft-list35-minerals-deemed-critical-us-national.

Elkind, Ethan. 2014. Reuse and Repower: How to Save Money and Clean the Grid with SecondLife Electric Vehicle Batteries. UC Berkeley, Center for Law, Energy \& the Environment. September 1, 2019. https://escholarship.org/uc/item/32s208mv.

Engel, Hauke, Patrick Hertzke, and Giulia Siccado. 2019. "Second-Life EV Batteries:

The Newest Value Pool in Energy Storage." McKinsey and Company. https://www.mckinsey.com/industries/automotive-and-assembly/our-insights/second-life-evbatteries-the-newest-value-pool-in-energy-storage.

EPA (U.S. Environmental Protection Agency). 2019a. "State Universal Waste Programs in the United States." Last modified August 30, 2019. https://www.epa.gov/hw/state-universal-wasteprograms-united-states.

- 2019b "State Authorization under the Resource Conservation and Recovery Act (RCRA)." Last modified May 21, 2019. https://www.epa.gov/rcra/state-authorization-underresource-conservation-and-recovery-act-rcra.

—. 2019c. "Hazardous Waste Manifest System.” Accessed July 19, 2020. https://www.epa.gov/hwgenerators/hazardous-waste-manifest-system.

- 2019d. "Differences between Universal Waste and Hazardous Waste Regulations." Last modified March 11, 2019. https:/www.epa.gov/hw/differences-between-universal-waste-andhazardous-waste-regulations.

—. 2019e. "What is a Hazardous Waste Permit?” Last modified June 10, 2019. https://www.epa.gov/hwpermitting/what-hazardous-waste-permit.

- 2019f. "International Agreements on Transboundary Shipments of Hazardous Waste." Last modified April 1, 2019. https://www.epa.gov/hwgenerators/international-agreementstransboundary-shipments-hazardous-waste.

- 2019g. "Frequent Questions on International Agreements on Transboundary Shipments of Waste". Last modified March 26, 2019. https://www.epa.gov/hwgenerators/frequentquestions-international-agreements-transboundary-shipments-waste.

- 2014. RCRA Orientation Manual. October 2014. https://www.epa.gov/sites/production/files/2015-07/documents/rom.pdf. 
. 2009. "Hazardous Waste Characteristics: A User-Friendly Reference Document."

October 2009. https://www.epa.gov/sites/production/files/2016-01/documents/hw-char.pdf.

Energy Storage Association (ESA). 2018. "ESA Contributes to Updating Fire Codes on Battery Energy Storage.” Accessed November 17, 2020. https://energystorage.org/esa-contributes-toupdating-fire-codes-on-battery-energy-storage/.

Evarts, Eric C. 2019. "Tesla Launches Battery Recycling at Nevada Gigafactory." Green Casr Reports. Accessed April 4, 2020. https://www.greencarreports.com/news/1122631 teslalaunches-battery-recycling-at-nevada-gigafactory.

FAA (Federal Aviation Administration). 2018. "Dangerous Goods Regulations for Air Transportation." Accessed August 10, 2020. https://www.faa.gov/hazmat/resources/regulations/.

Fan, Ersha, Li Li, Zhenpo Wang, Jiao Lin, Yongxin Huang, Ying Yao, Renjie Chen, and Feng Wu. 2020. "Sustainable Recycling Technology for Li-Ion Batteries and Beyond: Challenges and Future Prospects." American Chemical Society Chemical Reviews 120 (14), 7020-7063 (January 28, 2020). https://doi.org/10.1021/acs.chemrev.9b00535.

Gaines, Linda. 2018. "Lithium-Ion Battery Recycling Processes: Research Towards a Sustainable Course." Sustainable Materials and Technologies 17 (September 2018): e00068. https://doi.org/10.1016/j.susmat.2018.e00068.

- 2014. "The Future of Automotive Lithium-Ion Battery Recycling: Charting a Sustainable Course." Sustainable Materials and Technologies 1-2 (December 2014): 2-7. https://doi.org/10.1016/j.susmat.2014.10.001.

Gaines, Linda, Kirti Richa, and Jeffrey Spangenberger. 2018. "Key Issues for Li-ion Battery Recycling." MRS Energy \& Sustainability 5 (September 2018): 1-14. https://doi.org/10.1557/mre.2018.13.

Gerstin, Jesse. 2020. "The Case for Designing a Circular Battery." Greenbiz (March 5, 2020). https://www.greenbiz.com/article/case-designing-circular-battery.

Gibson, Trevor. 2019. "Lithium-Ion Battery Prices are Declining, Powering Growth and Opportunity in the U.S. Energy Storage Market. Smart Electric Power Alliance." Smart Electric Power Alliance. August 15, 2019. https://sepapower.org/knowledge/lithium-ion-battery-pricesare-declining-powering-growth-and-opportunity-in-the-u-s-energy-storage-market/.

Harper, Gavin, Roberto Sommerville, Emma Kendrick, Laura Driscoll, Peter Slater, Rustam Stolkin, Allan Walton, et al. 2019. "Recycling Lithium-Ion Batteries from Electric Vehicles." Nature 575, 75-86 (November 6, 2019). https://doi.org/10.1038/s41586-019-1682-5.

Huo, Haibo, Yinjiao Xing, Michael Pecht, Benno J. Züger, Neeta Khare, and Andrea Vezzini. 2017. "Safety Requirements for Transportation of Lithium Batteries." Energies 10(6): 793. https://doi.org/10.3390/en10060793. 
IATA (International Air Transport Association). 2019a. Lithium Battery Guidance Document, Revision 1: Transport of Lithium Metal and Lithium Ion Batteries. Accessed September 19, 2019. https://www.iata.org/whatwedo/cargo/dgr/Documents/lithium-battery-shippingguidelines.pdf.

—. 2016. Lithium Batteries as Cargo in 2016 Update III. Accessed September 19, 2019. https://www.iata.org/whatwedo/cargo/dgr/Documents/lithium-battery-update.pdf.

—. 2012. "Frequently Asked Questions." Accessed September 19, 2019. https://www.iata.org/whatwedo/cargo/dgr/Pages/faq.aspx.

ICC (International Code Council). 2018. “Code Adoption Map.” December 2018. https://www.iccsafe.org/wp-content/uploads/Code_Adoption_Maps.pdf.

IREC (Interstate Renewable Energy Council). 2017. "Charging Ahead: An Energy Storage Guide for State Policymakers.” April 2017. https://irecusa.org/2017/04/irec-releases-energystorage-guide-for-policymakers/.

Jacoby, Mitch. 2019. "It's Time to Get Serious About Recycling Lithium-Ion Batteries." Chemical \& Engineering News 97(28): 29-32. July 14, 2019. https://cen.acs.org/materials/energy-storage/time-serious-recycling-lithium/97/i28.

Jiao, Na. 2019. "Second-Life Electric Vehicle Batteries 2020-2030.” IDTechEx. Last modified August 2019. https://www.idtechex.com/en/research-report/second-life-electric-vehiclebatteries-2020-2030/681.

Kaufman, Sydney, Paul Komor, Blake Langdon, and Paul Vallett. 2011. "Electricity Storage in Regulated Markets: Getting the Rules Right." Electricity Journal 24(6): 63-71. https://doi.org/10.1016/j.tej.2011.06.006.

Kelleher Environmental. 2019. Research Study on Reuse and Recycling of Batteries Employed in Electric Vehicles: The Technical, Environmental, Economic, Energy and Cost Implications of Reusing and Recycling EV Batteries. Prepared for API by Kelleher Environmental. September 2019. https://www.api.org/ /media/Files/Oil-and-NaturalGas/Fuels/Kelleher\%20Final\%20EV\%20Battery\%20Reuse\%20and\%20Recycling\%20Report\%2 0to\%20API\%2018Sept2019\%20edits\%2018Dec2019.pdf.

Kumagai, Jean. 2021. "Lithium-Ion Battery Recycling Finally Takes Off in North America and Europe". IEEE Spectrum. January 5, 2021. https://spectrum.ieee.org/energy/batteriesstorage/lithiumion-battery-recycling-finally-takes-off-in-north-america-and-europe.

Mayyas, Ahmad, Darlene Steward, and Margaret Mann. 2019. "The Case for Recycling: Overview and Challenges in the Material Supply Chain for Automotive Li-Ion Batteries." Sustainable Materials and Technologies 19(April 2019): 19-e00087. https://doi.org/10.1016/j.susmat.2018.e00087. 
McCandless, Karen. 2019. "Still Got It: How Reuse and Recycling Can Give EV Batteries a New Lease of Life.” Automotive Logistics (April 15, 2019).

https://www.automotivelogistics.media/supply-chain-management/still-got-it-how-reuse-andrecycling-can-give-ev-batteries-a-new-lease-of-life/37938.article?adredir=1.

Neubauer, J., K. Smith, E. Wood, and A. Pesaran. 2015. Identifying and Overcoming Critical Barriers to Wideside Second Use of PEV Batteries. Golden, CO: National Renewable Energy Laboratory. NREL/TP-5400-63332. February 2015. https://doi.org/10.2172/1171780.

NFPA (National Fire Protection Association). 2020. "National Electrical Code." https://www.nfpa.org/codes-and-standards/all-codes-and-standards/list-of-codes-andstandards/detail?code $=70$.

North Carolina Department of Environmental Quality (NC DEQ) and Environmental Management Commission. 2021. "Final Report on the Activities Conducted to Establish a Regulatory Program for the Management and Decommissioning of Renewable Energy Equipment.” January 1, 2021. https://files.nc.gov/ncdeq/Environmental\%20Management\%20Commission/EMC\%20Meetings/ 2021/jan2021/attachments/AttachA-21-05-H329---FINAL-REPORT-Ellen--1-.pdf.

NREL (National Renewable Energy Laboratory). 2019a. "Your Renewable Energy Technology is Growing Old-What's Next?" April 22, 2019. https://www.nrel.gov/news/features/2019/yourrenewable-energy-technology-is-growing-old-whats-next.html.

- 2019b. Photovoltaics in the Circular Economy Workshop. March 1, 2019. Golden, CO: National Renewable Energy Laboratory.

- 2019c. "Competition Spurs Transformative Lithium-Ion Battery Recycling Solutions." February 28, 2019. https://www.nrel.gov/news/program/2019/competition-incentivizesamerican-entrepreneurs-develop-transformative-solutions-lithium-ion-battery-recycling-supplychain.html.

Pagliaro, Mario, and Francesco Meneguzzo. 2019. "Lithium Battery Reusing and Recycling: A Circular Economy Insight." Heliyon 5(6): e01866.

https://doi.org/10.1016/j.heliyon.2019.e01866.

Patel, Prachi. 2017. “How Green is Your Vehicle?” Energy Quarterly, Energy Section Analysis. June 2017. Cambridge University Press. https://doi.org/10.1557/mrs.2017.122.

PHMSA (Pipeline and Hazardous Materials Safety Administration). 2017a. "International Civil Aviation Organization.” Last modified September 1, 2017. https://www.phmsa.dot.gov/international-program/international-civil-aviation-organization.

_. 2017b. "International Maritime Organization.” Last modified September 1, 2017. https://www.phmsa.dot.gov/international-program/international-maritime-organization.

PowerScout. 2017. “2018 Solar Energy Storage and Battery Options: An In-Depth Guide.” PowerScout. Accessed May 17, 2020. https://powerscout.com/site/solar-energy-storage-battery- 
options-2018.

Purushottam Uniyal. 2020. Lithium-Ion Battery Recycling Market by Battery Chemistry (Lithium-nickel Manganese Cobalt, Lithium-iron Phosphate, Lithium-Manganese Oxide, LTO, NCA, LCO), Industry (Automotive, Marine, Industrial, and Power), and Region: Global Forecast to 2030. https://www.marketsandmarkets.com/Market-Reports/lithium-ion-batteryrecycling-market-153488928.html.

ReCell. 2019a. Novel Processing and Design Technologies Will Make Battery Recycling Profitable. February 2019. https://www.anl.gov/sites/www/files/2019-02/ReCell_FS.pdf.

- 2019b. ReCell Advanced Battery Recycling Center First/Second Quarter Progress Report 2019. Accessed September 19, 2019. http://blogs.anl.gov/recycling/wpcontent/uploads/sites/81/2019/08/2019_Q1Q2_ReCell_Quarterly.pdf.

- 2019c. ReCell Advanced Battery Recycling Center Fourth Quarter Progress Report 2019. Accessed June 4, 2020. https://anl.app.box.com/s/zi2rxa2d5ak4ayw7snqgfxfwj39vobct.

—. 2019d. "Modeling and Analysis." Accessed September 19, 2019. https://recellcenter.org/research/modeling-and-analysis/.

Richa, Kirti, Callie W. Babbitt, Gabrielle Gaustad, and Xue Wang. 2014. “A Future Perspective on Lithium-Ion Battery Waste Flows from Electric Vehicles." Resources, Conservation, and Recycling 83 (February 2014): 63-76. https://doi.org/10.1016/j.resconrec.2013.11.008.

Salim, Hengky K., Rodney A. Stewart, Oz Sahin, and Michael Dudley. 2019. "Drivers, Barriers and Enablers to End-of-Life Management of Solar Photovoltaic and Battery Energy Storage Systems: A Systematic Literature Review." Journal of Cleaner Production 211 (February 2019): 537-54. https://doi.org/10.1016/j.jclepro.2018.11.229.

Saxena, Samveg, Caroline Le Floch, Jason MacDonald, and Scott Moura. 2015. "Quantifying EV Battery End-of-Life Through Analysis of Travel Needs with Vehicle Powertrain Models." Journal of Power Sources 282 (May 2015): 265-276. https://doi.org/10.1016/j.jpowsour.2015.01.072.

SEIA (Solar Energy Industries Association). 2019. "SEIA National PV Recycling Program.” https://www.seia.org/initiatives/seia-national-pv-recycling-program.

Standridge, Charles, and Lindsay Corneal. 2014. Remanufacturing, Repurposing, and Recycling of Post-Vehicle-Application Lithium-Ion Batteries. Mineta National Transit Research Consortium. June 2014. https://transweb.sjsu.edu/sites/default/files/1137-post-vehicle-Li-Ionrecycling.pdf.

Steward, Darlene, Ahmad Mayyas, and Margaret Mann. 2019. "Economics and Challenges of Li-Ion Battery Recycling from End-of-Life Vehicles.” Procedia Manufacturing 33: 272-279. https://doi.org/10.1016/j.promfg.2019.04.033. 
Stringer, David, and Jie Ma. 2018. "Where 3 Million Electric Vehicle Batteries Will Go When They Retire." Bloomberg Businessweek. June 27, 2018.

https://www.bloomberg.com/news/features/2018-06-27/where-3-million-electric-vehiclebatteries-will-go-when-they-retire.

Suchak, Neal. 2020. Pipeline and Hazardous Materials Safety Administration: Lithium Battery Recycling and Reuse. U.S. Department of Transportation, Pipeline and Hazardous Materials Safety Administration. Webinar Presentation. January 23, 2020.

SWEEP (Solid Waste Environmental Excellence Protocol). "Time Is Running Out: The U.S. Landfill Capacity Crisis." 2019. https://nrra.net/sweep/time-is-running-out-the-u-s-landfillcapacity-crisis/.

Twitchell, Jeremy. 2019. "A Review of State-Level Policies on Electrical Energy Storage." Current Sustainable/Renewable Energy Reports 6:35-41 (April 22, 2019).

https://doi.org/10.1007/s40518-019-00128-1.

UL. "1741 Standard for Inverters, Converters, Controllers and Interconnection System Equipment for Use with Distributed Energy Resources.” Accessed September 19, 2019. https://standardscatalog.ul.com/standards/en/standard_1741_2.

—. 2014. "UL Rebuilt Equipment Certification Programs.” Accessed September 19, 2019. https://legacy-uploads.ul.com/wp-content/uploads/2014/04/ul_RebuiltEquipment.pdf.

—. 2019a. "1974 Standard for Evaluation for Repurposing Batteries." Accessed September 19, 2019. https://standardscatalog.ul.com/standards/en/standard_1974.

—. 2019b. "2020 NEC Addresses Electrical Safety: What Code Officials Need to Know." Accessed October 1, 2019. https://www.ul.com/news/2020-nec-addresses-electrical-safety-whatcode-officials-need-know.

- 2019c. "UL Issues World's First Certification for Repurposed EV Batteries to 4R Energy." Accessed July 31, 2020. https://www.ul.com/news/ul-issues-world\%27s-firstcertification-repurposed-ev-batteries-4r-energy.

USGS (United States Geological Survey). 2020a. "Mineral Commodity Summaries: Nickel." January 2020. https://pubs.usgs.gov/periodicals/mcs2020/mcs2020-nickel.pdf.

_. 2020b "Mineral Commodity Summaries: Tellurium."

https://pubs.usgs.gov/periodicals/mcs2020/mcs2020-tellurium.pdf.

Warren, Tamara. 2020. "Running on EV: The Race to Solve Lithium-Ion Battery Recycling Before It's Too Late." Fortune (January 28, 2020). https://fortune.com/2020/01/28/lithium-ionbattery-recycling-electric-vehicles/.

Wesoff, Eric. 2020. "More Records Set for U.S. Energy Storage Installs in Q4, Massive Growth Forecasted." PV Magazine (March 10, 2020). https://pv-magazine-usa.com/2020/03/10/esapower-capacity-record-for-us-energy-storage-installs-in-q4/. 
Wood Mackenzie, and ESA (Energy Storage Association). 2020. U.S. Energy Storage Monitor: 2019 Year in Review Full Report. March 2020.

World Bank Group. 2020. Minerals for Climate Action: The Mineral Intensity of the Clean Energy Transition. June 2017. http://pubdocs.worldbank.org/en/961711588875536384/Mineralsfor-Climate-Action-The-Mineral-Intensity-of-the-Clean-Energy-Transition.pdf. Washington, DC: The World Bank Group.

Yang, Jie, Fu Gu, and Jianfeng Guo. 2020. "Environmental Feasibility of Secondary Use of Electric Vehicle Lithium-Ion Batteries in Communication Base Stations." Resources, Conservation \& Recycling 156(May 2020): 104713.

https://doi.org/10.1016/j.resconrec.2020.104713.

\section{Court Cases}

Safe Air for Everyone v. Meyer, 373 F.3d 1035, 1041, 1043 (Ninth Cir. 2004)

\section{Executive Orders}

Exec. Order No. 13817, 82 Fed. Reg. 60835 (2017)

\section{Federal and State Statutes}

42 U.S.C. $\S \S 6901-6992 k$ (1976), Resource Conservation and Recovery Act

49 U.S.C. $\S \S 5101-5128$, Hazardous Materials Transportation Act

Cal. Health and Safety Code $\S 25189$

Cal. Pub. Res. Code $\S 42450.5$

\section{Federal and State Regulations}

40 C.F.R. § 19.4, 40 CFR § 19.4, Statutory Civil Penalties, As Adjusted for Inflation, and Tables.

40 C.F.R. $\S \S 260.1$ - 260.43, Hazardous Waste Management System: General.

40 C.F.R. $\S \S 261.1$ - 261.1090, Identification and Listing of Hazardous Waste.

40 C.F.R. $\S \S 262.1$ - 262.265, Standards Applicable to Generators of Hazardous Waste.

40 C.F.R. $\S \S 263.10$ - 263.31, Standards Applicable to Transporters of Hazardous Waste.

40 C.F.R. $\S \S 265.1$ - 265.1316, Interim Standards for Owners and Operators of Hazardous Waste Treatment, Storage, and Disposal Facilities.

40 C.F.R. $\S \S 266.20$ - 266.510, Standards for the Management of Specific Hazardous Waste Management Facilities.

40 C.F.R. $\S \S 268.1-268.50$, Land Disposal Restrictions. 
40 C.F.R. $\S \S 272.1$ - 271.27, Requirements for Authorization of State Hazardous Waste Programs.

40 C.F.R. $\S \S 273.1$ - 273.81, Standards for Universal Waste Management.

49 C.F.R. $\S \S 171-180$, Hazardous Materials Regulations.

49 C.F.R. $\S \S 171.1$ - 171.26, General Information, Regulations, and Definitions.

49 C.F.R. $\S \S 172.1$ - 172.822, Hazardous Materials Table, Special Provisions, Hazardous Materials Communications, Emergency Response Information, Training Requirements, and Security Plans.

49 C.F.R. $\S \S 172.300-172.338$, Marking.

49 C.F.R. $\S \S 172.400-172.450$, Labeling.

49 C.F.R. $\S \S 172.200-172.205$, Shipping Papers.

49 C.F.R. $\S \S 173.1$ - 173.477, Shippers - General Requirements for Shipments and Packaging. International Treaties

Basel Convention on the Transboundary Movements of Hazardous Wastes and their Disposal, Mar. 22, 1989, 1673 U.N.T.S. 57.

State Session Laws

2019 N.C. Sess. Law 2019-132.

State Bills

H.B. 1333, H.D. 1, 31st Leg., Reg. Sess. (Haw. 2021).

State Historic Bills

H.B. 2828, 54th Leg., 2d Reg. Sess. (Ariz. 2020) 


\section{Interviews}

Daniel Stoehr. Daniels Training Services, Inc. Teleconference. August 30, 2019.

David Wagger. ISRI. Email. August 3, 2020.

Jon Weisman. Formerly Tesla. Teleconference. August 30, 2019.

Ken Boyce. Underwriters Laboratory. Email. May 17, 2019.

Laura Allerston. Aceleron Energy. Teleconference, August 1, 2019.

Paulina Kolic and Teresa Bui. CalRecycle. Email. September 6, 2019.

Teresa Bui. CalRecycle. Email. January 8, 2021. 